\title{
Air-Leakage Control Manual
}

\section{Al? 91992}

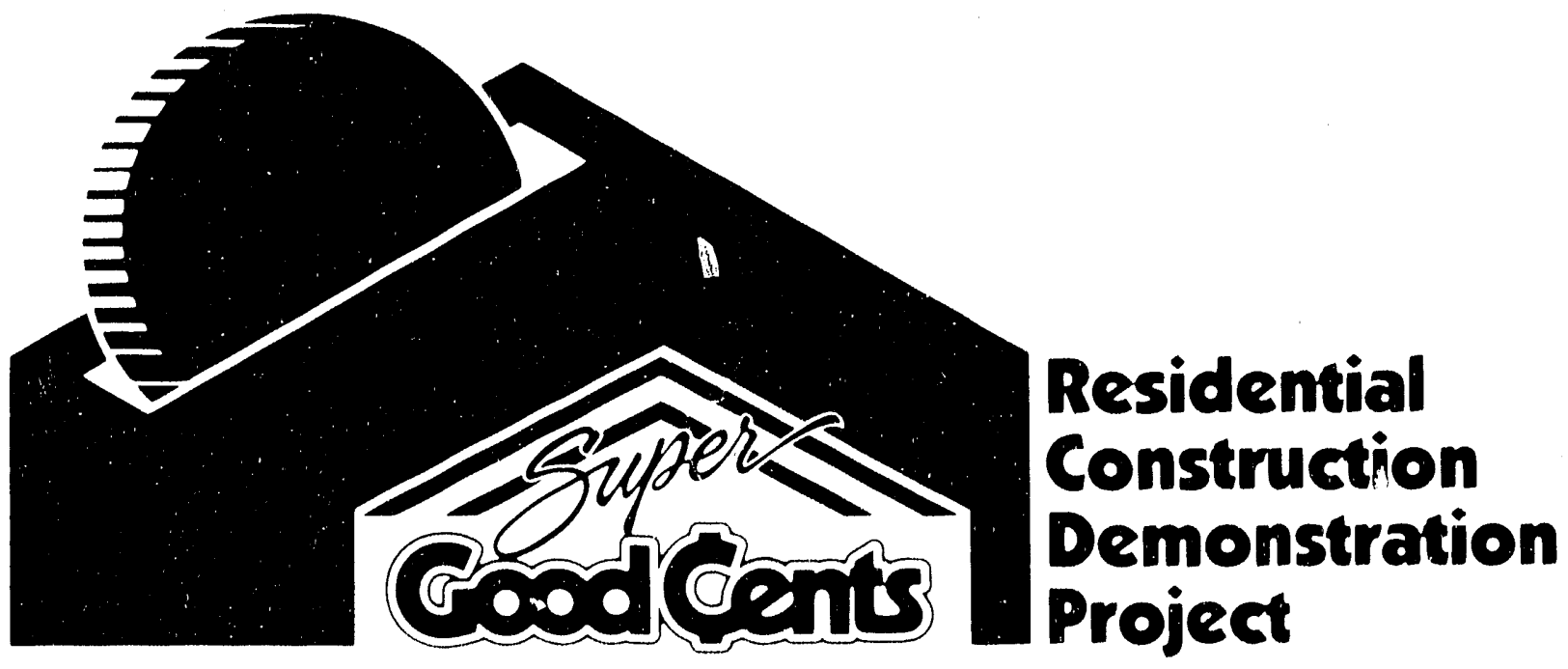




\section{Air-Leakage Control Manual}

Prepared for

Bonneville Power Administration's

Residential Construction

Demonstration Project

Under Contract Number 86-33-16

By Jim Maloney

Under Washington State Energy Office

Memorandum of Agreement Number 723

May 1991 


\section{Contents}

1. Introduction 1

2. Air Leakage in Homes 3

Forces Affecting Air Leakage 3

Effects of Forced-Air Heating Systems 3

Leaks in System Components 3

Differential Pressure 3

Benefits of Controlling Air Leakage $\quad 4$

Energy 4

Indoor Air Quality 5

Moisture and the Building Shell 5

3. Earlier Approaches for Controlling Air Leakage 7

The "Poly" Approach 7

The Advanced Drywall Approach 7

Problems with Earlier Approaches $\quad 8$

4. The SIMPLE-CS System 9

Floors over Crawlspaces 9

Floors over Basements and on Second Story 10

Connections between Floor and Exterior Wall 10

Intersections of Interior Partition and Exterior Wall $\quad 10$

Intersections of Interior Partition and Exterior Ceiling 11

Forced-Air Heating Systems $\quad 11$

5. SIMPLE•CS Analysis and Planning Procedure 
Appendix B. Completed SIMPLE·CS Analysis and Planning Pr ocedure for Sample Home

Outline of SIMPLE•CS Analysis and Planning Procedure

B-1

Plans for Sample Home: Main Level, Upper Level, and Section

B-2

Completed Air Sealing Checklist for Sample Home

B-.5

Appendix C. Sealing Materials

C-1

Adhesives

C-1

Caulks

C-2

Gaskets

C-2

Foams

C-3

Sheet Materials

Appendix D. Detail Drawings

D-1

Figure 1. Typical "ADA" Ceiling Detail

D-1

Figure 2. Intersection of Interior and Exterior Wall

D-2

Figure 3. "ADA" Wall Section at First and Second Floors

D.3

Figure 4. SIMPLE•CS Ceiling at Second Floor Level

D-4

Figure 5. SIMPLE•CS Ceiling at Exterior Wall/Floor Joint

D-5

Figure 6a. Intersection of Interior and Exterior Wall (Type 1)

D-6

Figure 6b. Intersection of Interior and Exterior Wall (Type 2)

D-7

Figure 7. Intersection of Interior Wall and Exterior Ceiling

D-8

Figure 8a. Sealing at Plumbing Peñetrations

D-9

Figure 8b. Sealing for Bathtub at Subfloor Cutout

D.10

Figure 9. Sealing Electrical Penetrations

D-11 


\section{Section 1. Introduction}

This manual is for builders and designers who are interested in building energyefficient homes. The purpose of the manual is to provide the "how and why" of controlling air leakage by means of a system called the "Simple Caulk and Seal" (SIMPLE.CS) system.

This manual is composed of the six sections and four appendixes described below.

Section 1 provides an overview of the purpose and contents of the manual.

Section 2 discusses the forces that affect air leakage in homes and the benefits of controlling air leakage.

Section 3 discusses two earlier approaches for controlling air leakage and the problems with these approaches.

Section 4 describes the SIMPLE-CS system. It outlines the standard components of the building envelope that require sealing and provides guidelines for sealing them.

Section 5 outlines a step-by-step procedure for analyzing and planning the sealing effort. The procedure includes (1) identifying areas to be sealed, (2) determining the most effective and convenient stage of construction in which to do the sealing, and (3) designating the appropriate crew member or trade to be responsible for the sealing.

Appendix $\mathbf{A}$ is an Air Sealing Checklist, indicating components of and penetrations in the building envelope that may require sealing. The checklist is a planning tool designed for indicating the areas to be sealed, the type of sealant to be used, the timing of the sealing, and the person responsible for doing it.

Appendix B consists of a completed analysis and planning procedure for a sample Northwest home. It includes (1) an outline of the steps involved, (2) plans and sections for the sample home, and (3) a completed Air Sealing Checklist for the home.

Appendix $\mathbf{C}$ discusses various sealing materials: adhesives, caulks, gaskets, foams, and sheet materials.

Appendix D includes detail drawings illustrating various points in the text (Figures 1-9). 


\section{Forces Affecting Air Leakage}

\section{Effects of Forced-Air Heating Systems}

\author{
Leaks in System \\ Components
}

\section{Differential Pressure}

\section{Section 2. Air Leakage In Homes}

The three forces that cause air to move in and out of buildings are stack effect, wind, and fans. Of the three, the stack effect causes the most uncontrolled air exchange. It occurs when there's a wintertime temperature difference between the air inside a home and outside. The difference in air densities causes cold outside air to infiltrate at the lower levels of a home and the inside air to exfiltrate at the upper levels.

Wind forces operate as you might think-infiltration on the windward or positive-pressure side of a home and exfiltration on the leeward or negativepressure side. Wind effects on the uncontrolled air exchange vary with local shielding and terrain conditions at the site. A home at an exposed site may have wind-induced infiltration three to four times as large as one more protected.

We have little control over the outdoor temperature or the strength or direction of the wind. Therefore, the only effective approach for minimizing stack and wind-force effects on infiltration is to minimize the "holes" through which the air can flow.

Forced-air heating systems affect the air exchange rates in homes in two ways: through leaks in the system components and by creating a pressure difference between parts of the home and the outside.

If the ductwork or the air handler is outside the heated space, the joints, seams, filter slots, plenum connections, and maintenance openings leak air, unless they are adequately sealed. The leakage is greatest when the system is on, because of the higher pressure differences created by the fan. But there is some leakage even when the fan is off, because the distribution system, commonly located in crawlspaces, basements, or attics, is effectively part of the building envelope. For example, return ductwork in the attic has warm indoor air rising into it even with the system off. This air can then leak into the attic. This leakage reduces the pressure in the lower portion of the home and allows air to leak from the crawlspace into the supply ducts and into the house.

A forced-air system works by creating a difference in pressure between the area where the supply registers are located and the area where the returns are located. A home with a forced-air system typically has a positive net pressure at the perimeter of the home and a negative net pressure near the central portion. For example, the bedrooms are usually pressurized and the hallway is depressurized.

The differential pressure leads to increased exfiltration in the bedrooms, because there is a greater difference in air pressure between the bedrooms and outside. It similarly leads to increased infiltration in the central portions of the home, commonly from the crawlspace, because of the proximity of large openings in the floor for plumbing and the ducts themselves. This situation is made worse whenever the bedroom doors are closed or the design of the system is such that the return side is "starved" for air. 


\section{Benefits of Control- ling Air Leakage}

\section{Energy}

Uncontrolled air leakage in a home affects not only the annual heating and cooling bills, but also the eflectiveness of ventilation systems and the long-term durability of the structure itself.

The heating load du. to infiltration can make up about a quarter to a third of a home's total spacedeat requirement. Often in newer homes buill with more efficient windows and iloors and higher levels of insulation in the walls, floors, and ceilings, little attention is paid to controlling air leakage. Builders believe they construct "quality" homes, and don't believe that a little infiltration is "that big a deal, after all, a house has got to breathe."

Of course, the size of the "deal" has a lot to do with the price of energy and the severity of the climate in which the home is built. The following graph shows the annual heating load and the annual $r$ sst of heating an 1800)-square foot home in the portland area. These estumates are for a reasonably well-insulated home with varying degrees of infiltration control. From about (0.3 air changes per hour (ACH) to a little over $0.5 \mathrm{ACH}$, the annual heating cost would increase by about $\$ 120$, assuming an electric rate of 4.5 cents per kilowatthour. It might cost about $\$ 250$ extra to build the house to the $0.3 \mathrm{ACH}$ levelwhich would yield a simple payback in about 2 years.

\section{Annual Heating Load and Heating Cost for Home (1800 sq. ft.) in Portland, Oregon}

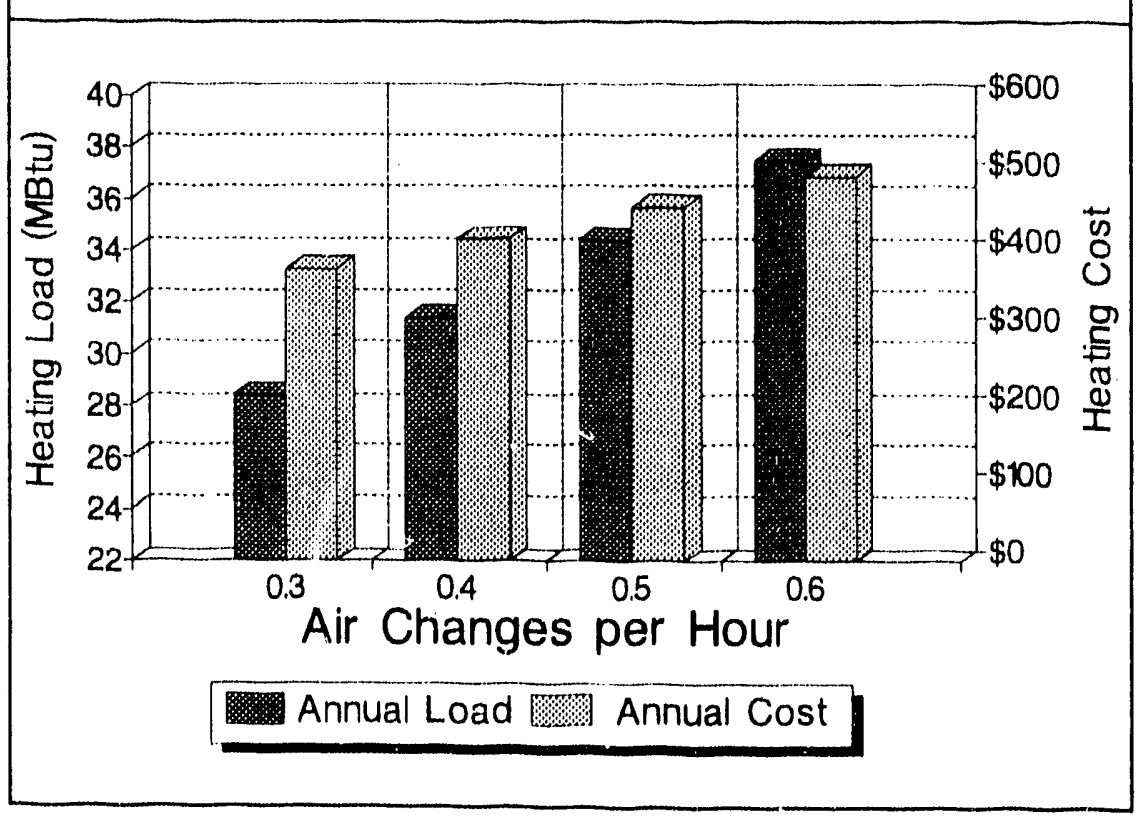




\section{Indoor Air Quality}

\section{Moisture and the Building Shell}

But now that the home has been built to save on heating energy, even more benefits are possible. If major pollution sources are not brought into the home, it's possible for the indoor air quality of the low-leakage home to be better than that in the old one that "breathed." When the ventilation rate of the home is less dependent on the uncontrolled air leakage, it's easier for a small mechanical ventilation system to adequately provide fresh air when and where it's needed. The system can be as simple as high-quality bath and kitchen fans combined with fresh air inlets for bringing outside air into the home.

In the case of some pollutants, like radon, an air-tight floor or basement can actuilly reduce the interior concentrations. Even tightening a ceiling cun reduce the entry of radon into a home by reducing the effective height of the stack effect, which pulls the soil gasses into the basement or from the crawlspace and into the home.

If it's fairly mild outside and there is no appreciable wind, the forces due to stack effect and wind pressure are absent. Without a mechanical ventilation system there would be no ail exchange in the home - ven with the windows open. The motto for good indoor air quality might be "Build tight and ventilate right."

Another benefit of reducing the amount of air leakage in homes is a decrease in the potential for future structural problems due to moisture-induced decay of the wood structure. As inside air leaks through walls and ceilings, it carries with it large amounts of water vapor generated within the home. The amount of moisture transmitted into building envelope assemblies by the leakage of moisture-laden air is much greater than that transmitted by diffusion. If the wall or roof sheathings are at a temperature below the dew point, a certain amount of the water vapor will be left behind, because it will condense on the cool surfaces. If this continues over an extended period of time, enough moisture can collect to support molds, fungi, and insect pests.

If the drying potential of the wall or ceiling assembly is not sufficient to remove the accumulated moisture during yearly cycles, there is a high likelihood of structural damage over time. Reducing the air leakage and providing a mechanical ventilation system are key strategies in extending the life of wood structures. 


\section{The "Poly" Approach}

\section{Section 3. Earlier Approaches for Controlling Air Leakage}

Two approaches previously recommended for controlling air leakage were the "Poly" Approach and the Advanced Drywall Approach.

Early in the 1980 s, some builders in the Northwest began experimenting with various techniques to limit air leakage. One technique was referred to as the "Continuous Polyethylene Air-Vapor Barrier" (PAVB). It was adapted from the Cantidian R-20(0) building program and from similar techniques used in factory-constructed houses in Sweden. The PAVB approach consisted of installing a continuous layer of polyethylene over the inner surfice of the exterior shell of the building - except where doors and windows were. At joints and seams the poly was carefully lapped and sealed.

Polyethylene sheet material was chosen because it could function as the air barrier and as the moisture-diffusion retarder. The idea was that since the same material could serve both functions, the re would be some cost savings. $T(1$ ensure continuity, some pieces of poly had to be installed during the roughframing stages of construction so that, later, the larger pieces covering the bulk of the walls and ceiling could be lapped and sealed to the pieces al reidly in place. The most common areas requiring lapping and sealing were the intersections of the interior partitions with exterior walls and ceilings.

Any penetrations in the PAVB had to be carefully treated. Because polyethylene is very flexible, it required some support or solid backing in order to be sealed around things like electrical boxes and duct penetrations. In addition, there were other complex tricks involved in getting a good seal around window and donr frames.

A number of builders had success with this approach. However, many who tried it found it too complicated for their continued use. Many of the homes built with the lechnique ended up only slightly less leaky than they would have been without it. This result was less a fault of the PAVB system than of the lack of attention to the forced-air heating systems and the multitude of minor penetrations in the building envelope.

The PAVB system was more appropriate for factory-constructed houses for which the materials could be assembled in a relatively clean areal, protected from the weather. In outdoor constuction, laced with rain, cold temperatures, and wet salwdust, builders had difficulty carrying out the air-barrier details.

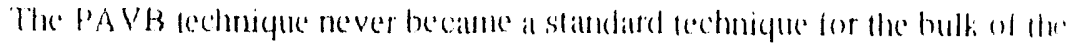
Nonthesest construction industry. White the issues of energy conservatiom. indow air quality, and mossture control were recognesed as impontant, mos,

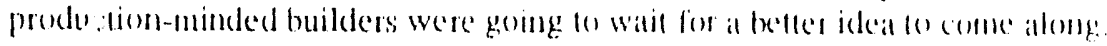
"The first one arrived on the scene around 1984, when Joe l stiburek and lim leischk off began promoting, something they called lle "Airtight brywall Ap proach" (ADA). Their ideas were organized into a system that tried to homs: air-leakage control techniques into the matistream of the production builder 
They recognized the problems with the PAVB system and proposed splitting the air-barrier and diffusion-retarder functions into two construction conponents.

Moisture diffusion could be handled in a number of ways. A builder could use faced insulation, foil-backed gypsun wallboard, or vapor-retarder paint to provide the required barrier. Because a moisture retarder's effectiveness is proportional to its surface area, a 95 percent vapor retarder is about as good as a 98 percent retarder-il can tolerate more imperfection than an air barrier can.

An air barrier needs to be able to resist air-pressure differences. Therefore, they thought, "Why not use parts of the building envelope that alrealy do that-like the gypsum-board walls and ceilings and the plywood floor'" "The trick on the air-barrier side was how to get the different structural components of the house to work together. The solution was to recognize that "effectively" continuous works as well as continuous.

While the drywall and the plywood subfloor served well as air-barrier surfaces, what was needed was some way to connect one surface to another. The ADA solution was to use a compressible gasket between components at transitions (see Figure 1; Figures 1-9 are shown in Appendix D). The gasket material could the applied prior to hanging the drywall, for example, and effectively carry the air-barrier surface from subfloor to bottom plate to drywall.

The eirly versions of ADA recommended running the gypsum boara between tixe last stud in a partition wall and the exterior wall framing. It also suggested running the gypsum board between the top plate of an interior partition and the underside of the trusses or ceiling joists. These details were later modified in practice to those now used (see Figure 2), Over time, and with a few more modifications, builders around the country were using ADA in one form or another and its name had evolved into the "Advanced Drywall Approach."

But, even with ADA, there were problems and requests for "a simpler way." II was still necessary to have the framing crew apply gasketing between structural members during construction (see Figure 3). And many of the air-sealing tasks still had to be completed before the building shell was weathertight.

\section{Problems with Earlier Approaches}

The problems with the earlier air-barrier approaches were partially a result of the techniques themselves and partially a result of the impracticality of implementing them in the real world of construction.

- They require detail-oriented work at an inappropriate stage of construction.

- They require an interruption in the normal flow of work on a building site.

- They tend to emphasize techniques for sealing the floor, wall, and ceiling assemblies at the cost of attention to sealing the multitude of penetrations.

- They fail to recognize the law of diminishing retums, resulting in greater effort and increased costs.

Air-tightening a building is not an all-or-nothing proposition. The earlier approaches were too comprehensive, too complicated, and too unt rusting of simpler solutions. As a result of this realization, another approach was developed to address the most common requests of builders. This new approach, called the "Simple Caulk and Seal" (SIMPLE.CS) system, is discussed in the next section. 


\section{Floors over Crawlspaces}

\section{Section 4. The SIMPLEoCS System}

The "Simple Caulk and Seal" (SIMPLE•CS) system attempts to minimize the effort required to reduce air leakage in residential buildings. The idea behind this system is simple-reduce the number of sealing steps and delay them until as late as possible in the construction process. This approach is based on the notion that no matter how good a job is done on the major components (like walls and ceilings), unless attention is pald to all the penetrations, the overall quality of the job will suffer.

The SIMPLE $\cdot$ CS system consists of only two parts:

- The plywood subfloor and gypsum-board wall and ceiling finishes (excellent air-barrier materials that represent 90 percent of the air barrier in the SIMPLE•CS, system).

- A standard set of other components and penetrations in the building envelope that require sealing.

In order to coordinate the air-sealing $\mathrm{effort}$, a step-by-step analysis and planning procedure has been developed (see Section 5). This procedure is designed to help a builder or designer determine what needs to be sealed, when in the construction process the sealing should be done, and who should do it.

The analysis and planning procedure includes taking an inventory of potential leakage sites for a specific home. To aid in their identification, a comprehensive checklist of possible leakage sites is included in Appendix A. An example of this procedure, completed for a sample home, is included in Appendix B.

Guidelines for sealing the standard components of the building envelope are presented below with a focus on details typical in site-built homes in the Pacific Northwest. Possible penetrations in the building envelone that also may require sealing are included in Section 5 .

Construction materials and techniques other that those presented may require modifications of these recommendations. Suggestions for appropriate caulking and other sealing materials are provided in Appendix C.

In spite of what was said earlier about sealing after the home is framed and sheathed, floors over crawlspaces are easiest to seal while the subfloor is being laid (though it can be done at a later time). Most builders ușe adhesives in addition to nails or staples to attach the tongue and groove plywood or waferboard to the floor structure. This provides an excellent opportunity to seal the floor. The following procedure will result in an air-tight subfloor that runs con]. tinuously under all exterior and interior walls.

- To seal the short dimension of the sheet, apply a continuous bead of glue on the joist at the butt joint of the floor sheathing. 


\section{Floors over Basements and on Second Story}

\section{Connections between Floor and Exterior Wall}

\section{Intersections of Interior Partition and Exterior Wall}

- I'o seal the long dimension, simply add a bead of adhesive to the bot. tom side of the tongue before laying the sheet down and snugging it into place. By placing the glue on the bottom of the tongue, you ensure that any glue forced out when the sheets are brought together will squeezc out on the underside, not on the top where it can be tracked around.

The main leakage site in these floors is at the rim joist area. These floors can usually be sealed after framing, unless there will be constricted access. For example, access would be limited if the last joist bay was only 12 inches wide or the joists were only $2 \times 8 \mathrm{~s}$ (which would leave $71 / 2$ inches of vertical space in which to work once the subfloor above was laid). A suggested approach is to handie the insulation, air sealing, and moisture diffusion all at the same time.

- Install several inches of rigid insulation as a thick block against the rim joist and caulk around all edges-to the mudsill or top plate, to the joist on either side, and to the subfloor above (see Figure 4).

- For a basement home, seal the joint between the mudsill and the foundation.

- For a two-story home, seal between the top plate of the lower wall and the gypsum-board wall covering.

Typically, builders use caulks or gaskets under the bottom plate of an exterior wall and then apply another gasket or drywall adhesive between the bottom plate and the wallboard. With SIMPLE.CS, all you need to do is the following:

- Seal the joint between the subfloor and the gypsum board, or other interior wall covering (see Figure 5).

Sealing this joint eliminates the necessity of having the framing crew deal with an additional step while they're trying to put up the building shell. It also makes it possible to do the sealing work after the drywall is up and the home is weather-tight. This step can be postponed until just before the finish floors go down.

In order to keep any air that leaks into the exterior wall out of the interior partition (or vice versa), you need to seal the area where they intersect. This is most easily accomplished after framing is completed and the shell is insulated.

- Seal the interior-wall gypsum board to the last stud in the interior partition with a continuous bead of drywall adhesive. The adhesive should run from the subfloor to the top of the top plate.

OR

- Install a length of compressible gasiet between the wallboard and the last stud. The gasket can be applied all at once, in advance of the drywall application, or a worker can do a room at a time ahead of the crew hanging the drywall on the walls and ceilings (see Figures fa and 6b). 


\section{Intersections of Interior Partition and Exterior Ceiling}

\section{Forced-Air Heating Systems}

This connection is handled like the wali intersection.

- Seal the partition-syall gypsum board to the top plate of the partition wall with either a continuous bead of adhesive or a compressible gas. ket (see Figure 7). This effectively seals off the interior wall cavities from the attic or roof above.

The design and installation of the heating system has a major impact on the success of any tightening approach. A home with an otherwise air-tight envelope may still have unacceptably high infiltration levels, if the heating system is not designed and installed appropriately. The following guidelines will minimize the negative impact of the HVAC system on the air exchange rate.

- Try to get the heating plant and the ductwork inside the heated envelope. That way, any air that leaks out will still provide heat to the home, and outside air cannot be pulled into the retum side of the system. In homes with basements this is fairly easy. In homes with crawlspaces, try running a dropped soffitt in the hallway and locating the mechanical room in a centrit location.

- If ductwork must bo run outside the insulated shell, make sure it is well sealed. Ductwork to be sealed includes not only the joints between lengths of duct, but also the long seams in metal duct and any crimped edges on plenum bexes or register boots. Use a high-quality tape or a sealant specifically designed for ductwork (such as AIR-LOCK: see Caulks ir Appendix (). Remember that metal duct often has a thin coating of oil remaining from the fabrication process. This oil must be wiped off in order to get any sealing material to stick for very long. A rag with mineral spirits usually will do the trick.

- Design the system in such a way that the supply and return portions are in balance. This may mean using more returns than you normally do. Bedroom doors should be undercut a minimum of $3 / 4$ inches, if there is no return in the bedroom. Other options are louver doors or open transoms to the hallway. 


\section{Section 5. SIMPLE॰CS Analysis and Planning Procedure}

This step-by-step dnalysis and planning procedure was developed to help coordinate the air-sealing effort, so that the sealing gets done in the appropriate places and at the most effective and convenient stage of construction. It is designed to guide you in determining where sealing is required, when it should be done, and by whom. As potential leakage sites are identified, you can use the Air Sealing Checklist (Appendix A) to record this information.

To complete this procedure for a specific home, you will reed floor plans and section drawings of the building sufficient to indicate all pertinent information about the building geometry and the placement of major components. As an example, the SIMPLE. $C S$ analysis and planning procedure has been completed on a sample Northwest hom: (see Appendix B). Recommended sealing materials are discussed in Appendix $\mathrm{C}$.

\section{Step 1 Identify and indicate on the floor plans and sections the exterior zone boundary (EZB) of the building.}

Indicating the location of the EZB may seem to be a waste of time. However, experience has shown that we are often unclear about whether a particular wall, or part of a wall, is an "inside wall" or an "outside wall." Differentiating between the two is a critical step for homes with more than one floor leveltwo story homes, homes with basements, split levels, etc. In these cases, it is common to forget where the outside is in relation to the inside. For example, you might have to stop and think about areas such as stairways and common walls.

Overhangs and cantilevers are other areas we often overlook. They usually end up getting insulated and soffitted, but our attempts at air sealing are often not as successful as they might have been had we remembered them before the drywall was hung.

A good way to carry out this step is to use a highlighter-type marker on a set of working drawings to indicate the elements of the house that act as the divider between inside and outside. Once these are highlighted, you can see at a glance where the air barrier probably needs to be-the inside surface of the EZB.

\section{Step 2 Identify on the plans and sections the locations of discontinuities in the materials that will make up the air-barrier surface of the EZB (exterior walls, floors, and ceiling:}

The obvious locations are the joints between wifferent building elements, such as gypsum wallboard and plywood subflovi. Other locations include areas sicch as a plywood subfloor that is actually made up of $4^{\prime} \times 8^{\prime}$ pieces with joints between them at the edges. If the edges aren't sealed in some way, they can act as holes in the envelope. 


\section{Step 3 Determine the type of sealing necessary and at what stage of construction it should be done in order to make the EZB effectively continuous.}

Joints between components of the EZB tend to fall naturally into two groups. The first group requires attention before the insulators or some other building trade makes it impossible or difficult to do the sealing work. Examples in this group include rim joist areas in two-story or basement homes and stairway framing. Sometimes the actual sealing work is not necessary at this time, but an extra line of blocking or the judicious placement of required fire-blocking can make it easier to do later.

The plywood subfloor joints (mentioned in Step 2) are easiest to seal while the floor is being laid. They can be sealed by applying continuous beads of subfluor adhesive at the butt joints on framing members and putting a bead on the bottom of the tongue before the panels are knocked together.

The second group requires attention after the gypsum board has been placed on the walls and ceilings. The board joints themselves are typically taped and finished. The joint between the wallboard and the subfloor can be caulked or foamed.

\section{Step 4 Find and indicate on the plans and sections all
intersections of the interior partitions with the EZB.}

These intersections can typically be circled on the drawings with a contrasting color. What we need to know is the configuration of the particular intersection and all the places it occurs. You need to remember that not all partitions show up on the sections. Hopefully, enough have been drawn to characterize t;pical conditions.

This step identifies the following kinds of intersections:

- Interior wall to exterior wall

- Interior wall to exterior ceiling

- Balcony half-wall to exterior wall

- Interior wall to exterior roof/ceiling assemblies in split levels

- Interior second floor assembly to exterior wall in two-story and basement homes 


\section{Step 5 Determine the type of sealing to be used for each of the
intersections. Determine at what stage of construction (timing) the sealing should be done and by whom.}

From the floor plan and the sections, you need to generate typical framing details. You can then decide on the placement of the gasket, bead of caulk or adhesive, or foam application that will seal the critical joint( $(s)$ in the detail. After this is determined you can decide whether the seal can wait until after the gypsum board is hung or if it needs attention before some other trade makes the seal more difficult to accomplish.

Many of the solutions for these air-sealing problems are already available in nanuals prepared for the Bonneville Power Administration. 1,2 Others are aasily arrived at once the determination has been made as to where and when lize seal is to be made. Examples of the solutions are included in this manual (see Figures 2-9 in Appendix D).

Nearly as important as determining the type of sealing and the timing of the seal is designating the responsibility to a particular trade. If the construction crew is not going to be handling a particular aspect of the sealing work, at this point you can start putting together lists for the subcontractors.

\section{Step 6 Locate on the plans and sections all arcas where the EZB is penetrated by or composed of the items in Group " $A$ " of the Air Sealing c"ac:slist. For each item, determine the type of sealing, the timing, and the responsible trade.}

Groun A of the Air Sealing Checklist consists of the major strintural openings in the building invelope and other complicating framing features. Details as to how the air sealing is to be accomplished for each item must be determined at this time.

These items are large enough that they typically show up on most good sets of building plans. It's sometimes a good idea to number the item on the plan or section so that it can be referenced in either a secondary list or a set of detail sheets.

Doors, windows, and skylights need to be considered so that the sealing is done in concert with the installation of the units and whatever the accompa , ing interior trim-out will be. Areas such as dropped ceilings, soffitted assemblies, and furred spaces also need consideration. Should the air barrier go inside the volume created or should it be carried out around the outside? Stairways and bathtubs are troublesome spots because of their common adjacency to other interior walls and components (see Figure 8b). Details and ideas can be worked out with work crews and subcontractors.

1 Oregon State University Extension Energy Program. Builder's Field Guide. Prepared for the Bonne ville Power Administration. October 1990.

2 Oregon State University Extension Energy Program. Residential Construction Reference Mamual. Prepared for the Bonneville Power Administration. October 1990. 
Locate on the plans and sections all points where the EZB is penetrated by the items in Group "B" of the Air Sealing Checklist. For each item, determine the type of sealing, the timing, and the responsible trade.

The items in Group B do not always show up on the building plans in their actual locations. Often it is assumed that their placement will simply be carried out in conformance with applicable codes. Even though this is the cuse, it's important to consider the number and types of these penetrations. Often it's possible to minimize the number of penetrations of the EZB by consulting the appropriate subtrade or by considering alternate placement of equipment.

In considering placement of equipment, you might ask the following questions, for example:

- Is it possible to get most of the heating ductwork inside the heated envelope?

- Can recessed lighting in an exterior ceiling be replaced with well-designed surface-mounted fixtures? Or can they be placed in a soffitted area with the air barrier between the soffitted volume and the EZB'?

- Can the medicine cabinet be moved to an interior wall?

This step is also important for determining how the chimneys, flues, and plumbing stacks will be sealed. Typically, these areas are not sealed successfully with foams. It's at this stage that altematives can be discussed and decided on. A common cause of failure in air-sealing attempts is not having the right material on the job at the right time. For example, if you are using a piece of EPDM sheet as the air-barrier collar to be slif ped over plumbing stacks where they penetrate top plates. you ideally should have them on site for the plumber to slip on the pipe when it goes through the plate (see Figure 8a). You can easily staple one near the entry point of each drain line or vent stack so that the plumbing sub can put it over the pipe for sealing at a later date.

\section{Step 8 For the items in Group "C" of the Air Sealing Checklist, determine the type of sealing, the timing, and the responsible trade.}

The items in Group $\mathrm{C}$ tend to be the smaller holes in the house. Typically, these items also are only schematically indicated on the drawings, if at all (plumbing runs are rarely shown for example). However, the same decisions need to be made for these items as those made for the penetrations already addressed. Consider the typical cases and decide accordingly.

An important thing to keep in mind is that holes in the exterior framing, where wire and water-supply pipes run, do not need to be sealed. They are a concem only when the holes occur at the connection between inside and outside, that is "through" the EZB.

Some of these items, like others in Groups A and B, may have more than one trade or subcontractor as a possible person to do the sealing. The appropriate choice depends on the builders' knowledge of the capabilities and costs of their subs and their crew members. 


\section{Step 9 Include in the contracts for the appropriate trades the items from the checklist they are responsible for. Include a descrip- tion of the type of sealing desired. Indicate by what point in the construction process the sealing shall be completed fior ench item.}

The decision regarding the responsible trade has already been made and entered on the Air Sealing Checklist. Therefore, it's now relatively simple to extract an individual list for each of the subcontractors with sealing responsibllities.

At this point, it may make sense to modify the list. For example, you might decide to go with a single air-sealing subcontractor rather than a number of subtrades. Or you may decide to simply have your own crew take on the job, since there is usually a crew member on site even when the other subs are there.

The list can be refined by considering questions such is the following:

- Are too many trades involved?

- Is the plumber doing only two things?

- Will the particular subs do a good job or would they rather just be responsible for their usual duties?

- Who should be responsible for providing the sealing materials?

An important issue to clarify with the so' $x$ contractors is at what point the sealing shuald be completed for their particular item(s). If construction is delayed because the work of one sub isn't finished in time, you will need to consider ways to get back on schedule.

\section{Step 10 Determine if blower door testing will be required and,
if so, at what point.}

One of the only ways to actually determine the tightness of construction is by blower door testing the home. This testing is a final exam, so to speak. It usually occurs when all air sealing has been completed and acts as the measured result for that home. A large fan and support-bracket assembly is temporarily installed in an open door of the home. While the fan is operated at various speeds, a series of pressure and air-flow measurements are made. These data can be analyzed to give an indication of the fotal leakage area of the home.

An alternative is to engage an air-sealing or fan door contractor to do a preliminary diagnostic test on the home while many of the seals are still accessiblefor example, before the attic insulation is blown, or before carpets, pads and baseboards are installed. While the home is depressurized by the blower door. it is easy to identify the areas where air is rushing in. They can be identified by means of a small smoke-producing device (a "smoke-stick") or even your hand. This approach allows you to test and improve the quality of the sealing work. 
Appendix A Air Sealing Checklist 


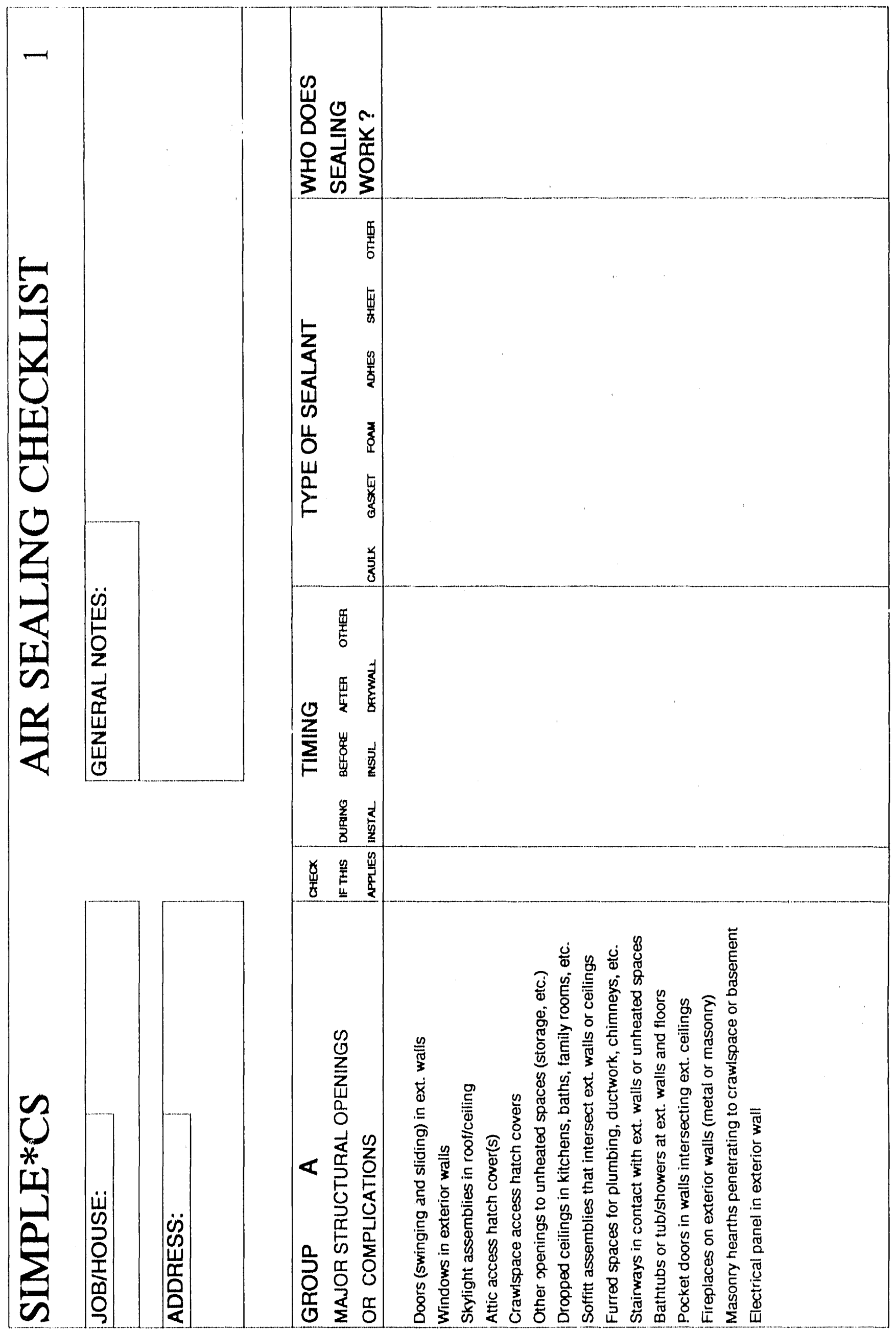




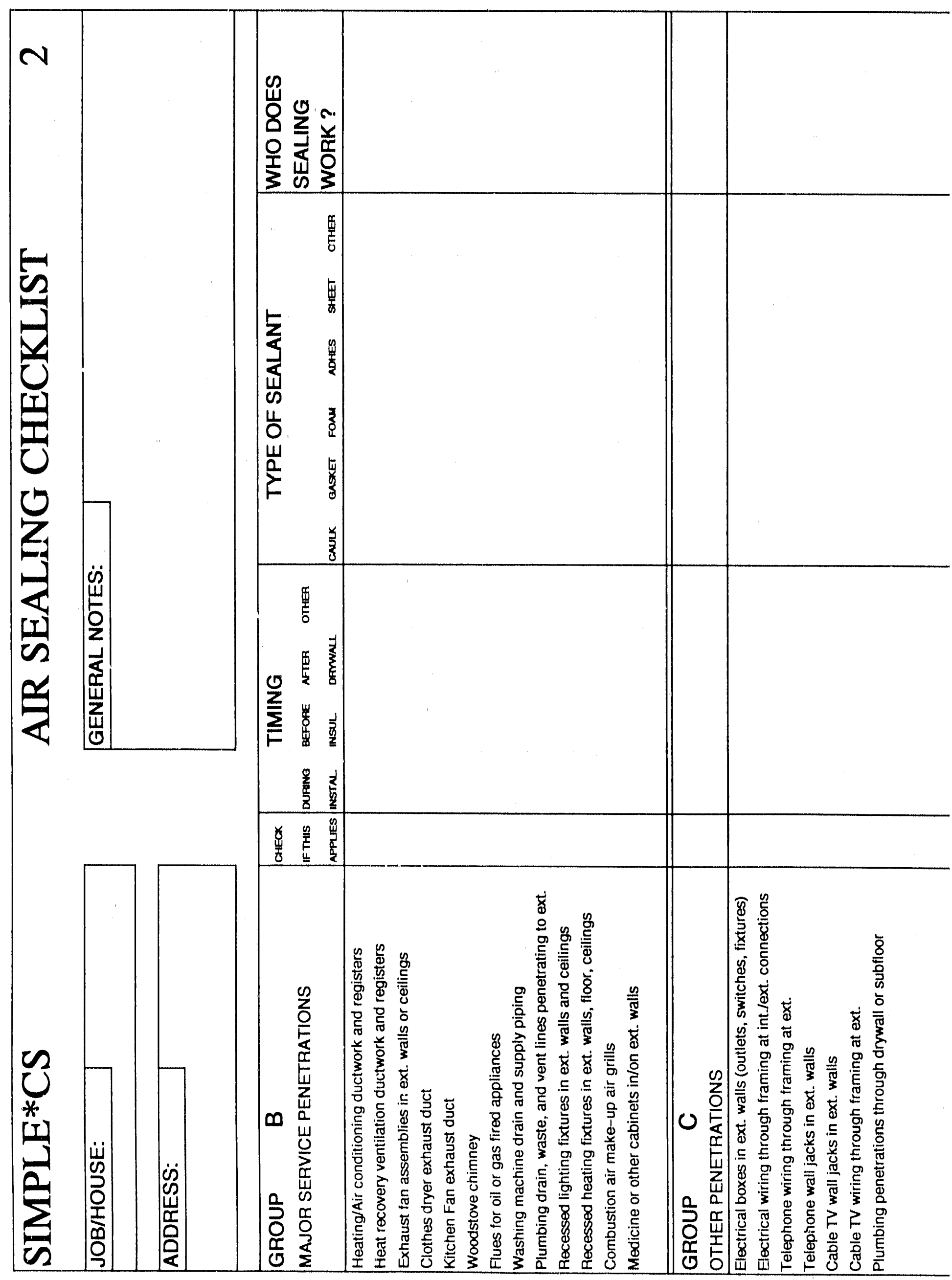




\section{Appendix B}

Completed SIMPLE-CS Analysis and Planning Procoduro for Samplo Home 


\section{Outline of SIMPLE•CS Analysis and Planning Procedure}

\section{Appendix B. Completed SIMFLEoCS Analysis and Planning Procedure for Sample Home}

Step 1 Identify and indicate on the floor plans and sections the exterior zone boundary (EZB) of the building. Step 2 Identify on the plans and sections the localions of discontinuitics
in the materials that will make up the surface of the EZB (exterior walls, floors, and ceilings).

Step 3 Determine the type of sealing necessary and al what stage of construction it should be done in order 10 make the EZB effectively continuous.

Step 4 Find and indicate on the plans and sections all intersections of the interior partitions with the EZB.

Step 5 Determine the typi of sealing to be used for eakis if the intersections. Determine at what stage of constructic ti (timing) the sealing should be done and by whom.

Step 6

Locate on the plans and sections all areas where the EZB is penetrated by or composed of the items in Group "A" of the Air Sealing Checklist. For each item, determine the type of sealing, the timing, and the responsible trade.

Step 7 Locate on the plans and sections all points where the EZB is penetrated by the items in Group " $B$ " of the Air Sealing Checklist. For each item, determine the type of sealing, the timing, and the responsible trade.

Step 8

For the items in Group " $\mathrm{C}$ " of the Air Sealing Checklist, determine the type of sealing, the timing, and the responsible trade.

Step 9 Include in the contracts for the appropriate trades the items on the checklist they are responsible for. Include a description of the type of sealing desired and indicate by what point in the construction process the seating shatl be completed. Step 10 Determine if blower dow testing will be required and, if so, all
whal point. 
Figure 6a

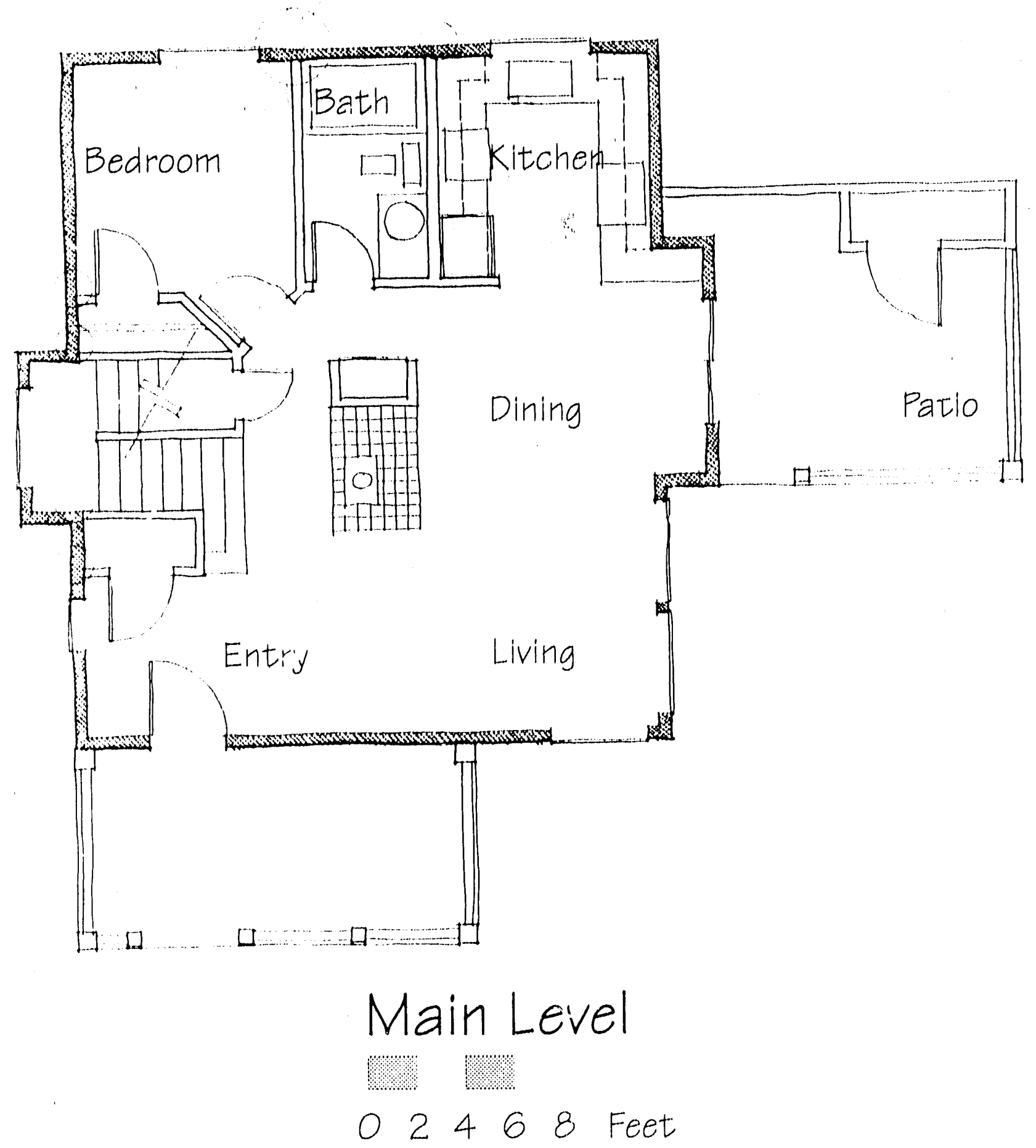

- Step 1: Identify the E.Z.B.

Step 2: Plywood Subfloor Joints,

Drywall/Subfloor Joints, Drywall

Joints

Step 4: Intersections -- See Details 
Figure 86

Figure $6 a$

Figure $6 b$

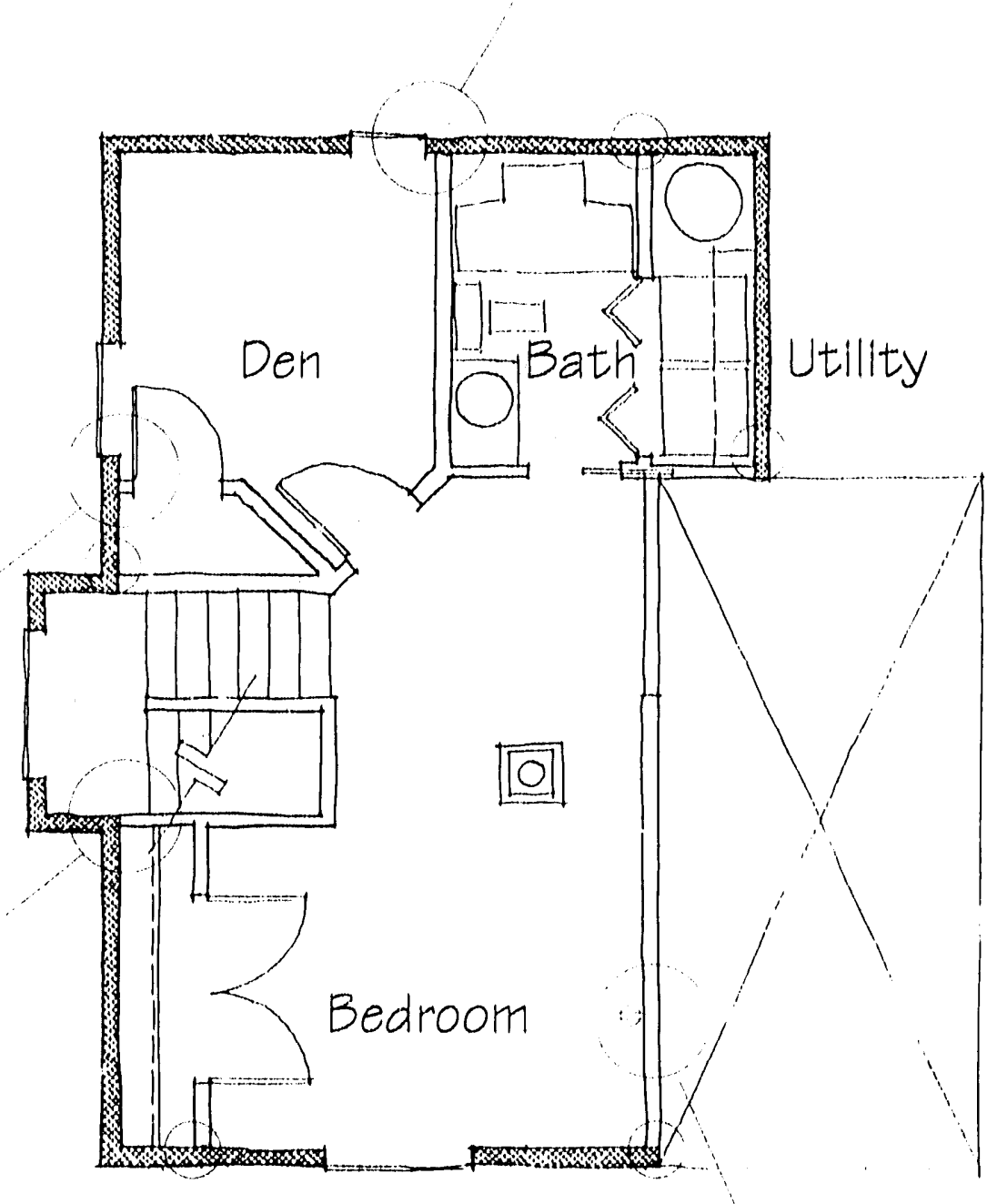

Figure 9

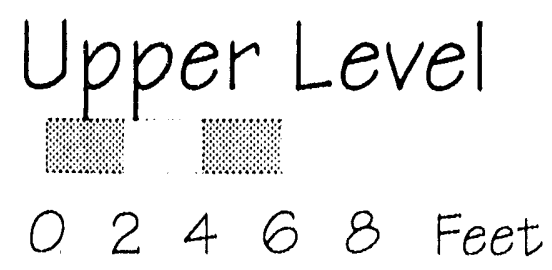

Step 1: Identify the E.Z.B.

Step 2: Plywood Subfloor Joints,

Drywall/Subfloor Joints, Drywall

Joints

Step 4: Intersections -- See Detalls 


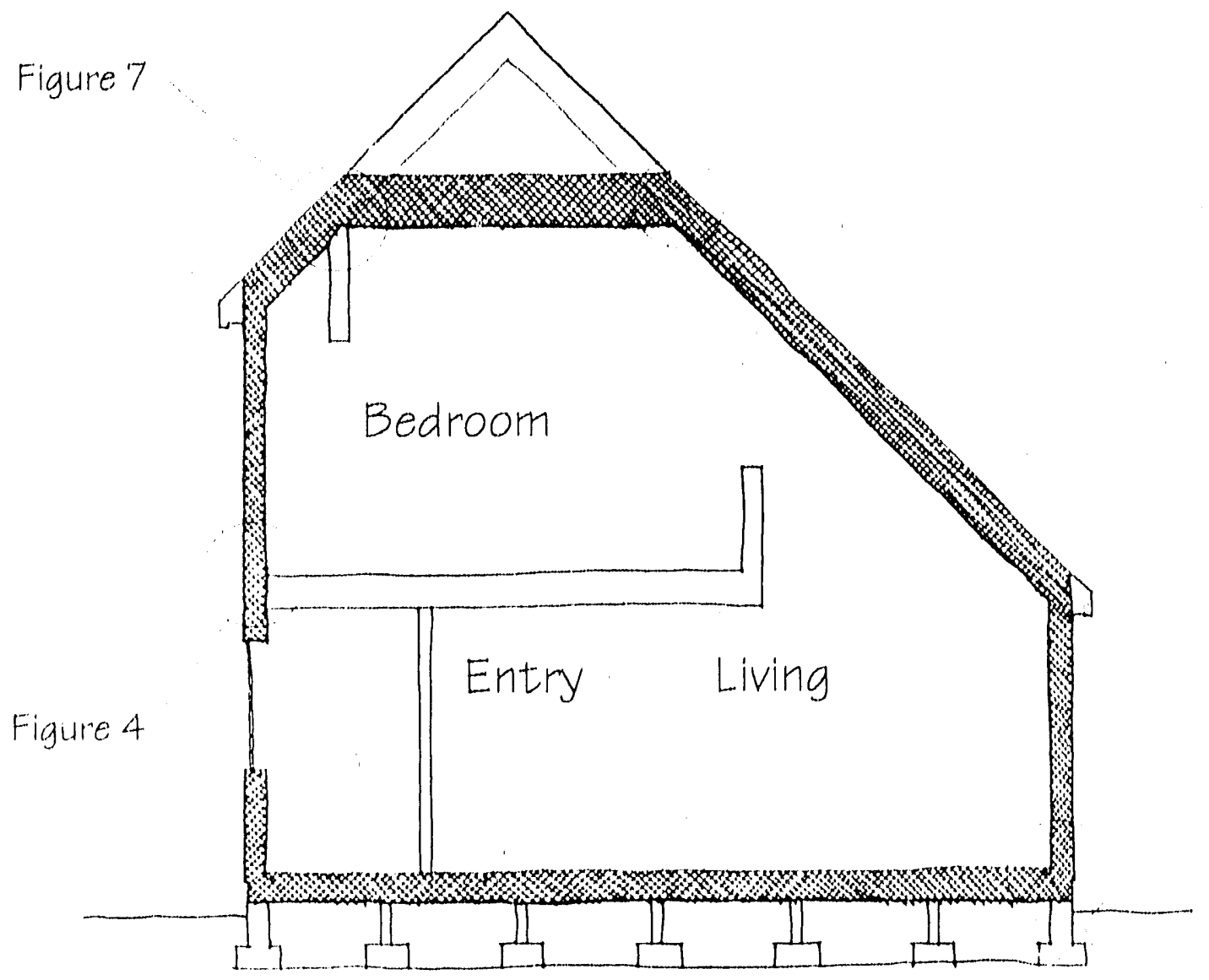

Section

Figure 5

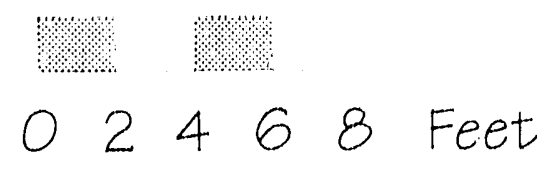

1. Step 1: Identify the E.Z.B.

Step 2: Plywood Subfloor Joints, Drywall/Subfloor Joints, Drywall

Joints

Step 4: Intersections -- See Details 


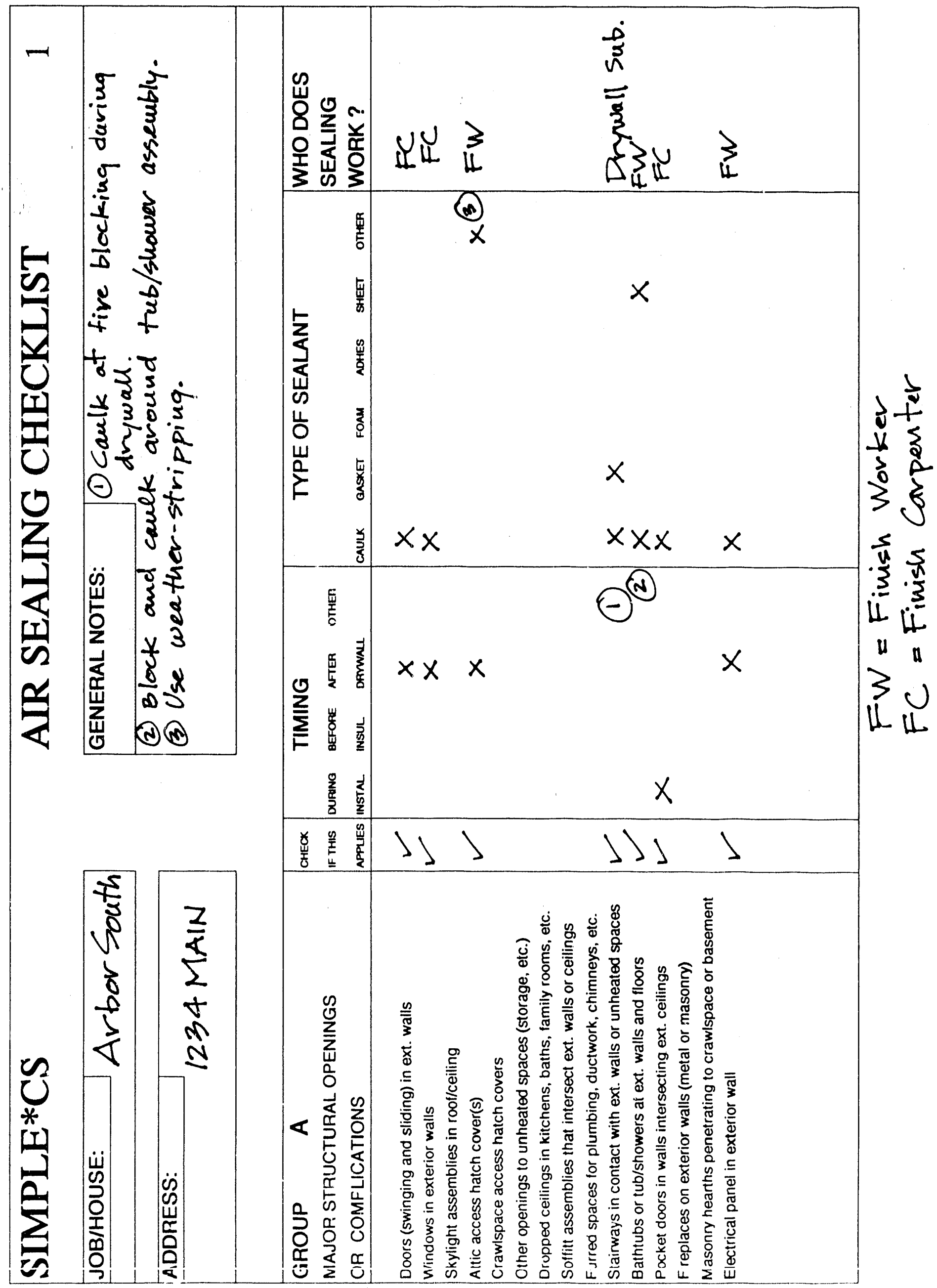




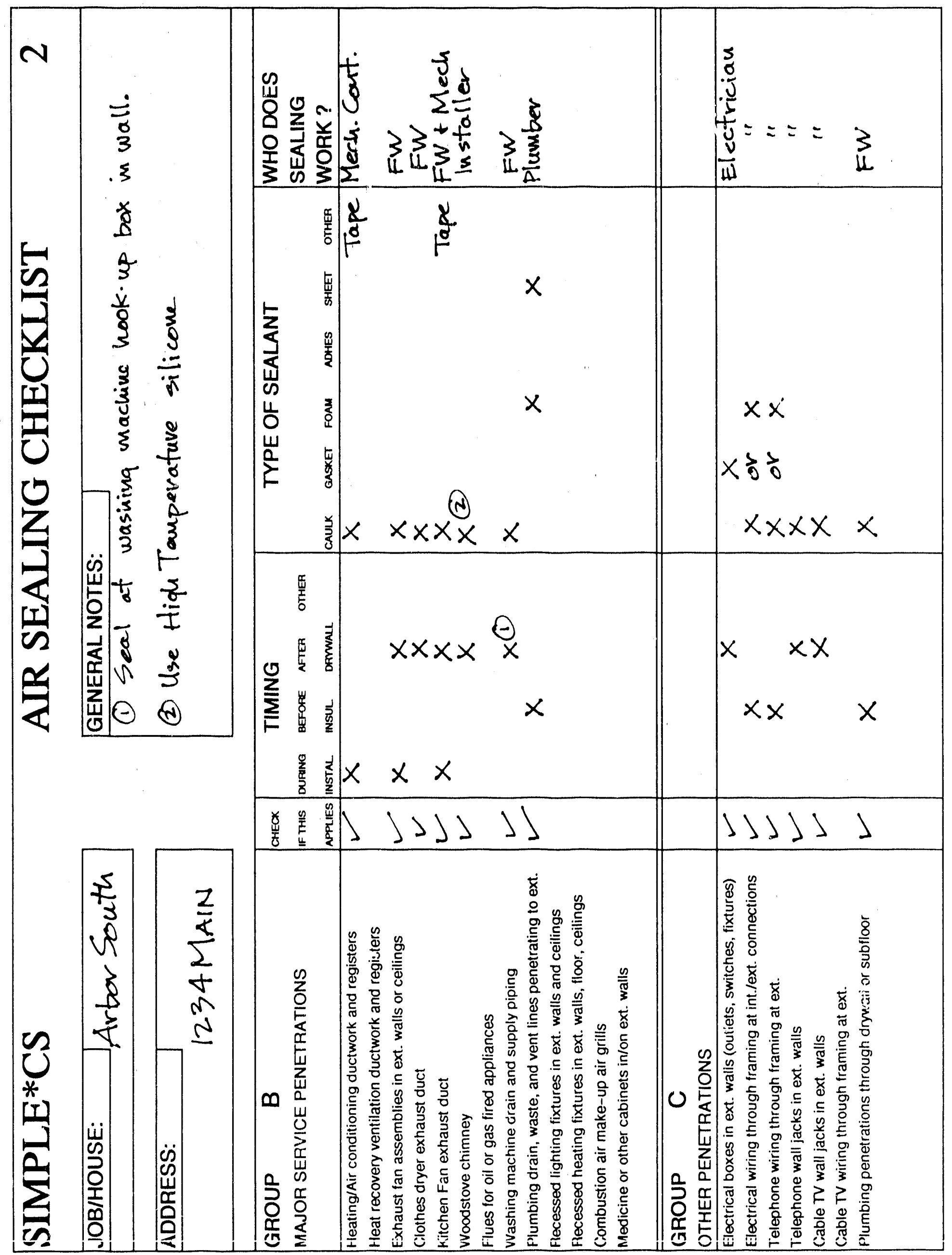




\section{Appendix C}

Sealing Materials 


\section{Adhesives}

\section{Uses}

\section{Adhesive Products}

\section{Appendix C. Sealing Materials}

Five types of sealing materials are discussed in this appendix: adhesives, caulks, gaskets, foams, and sheet materials.

Adhesives are already in common use on nearly all job sites. They are commonly used for the joints in plywood subfloors and for sealing the drywall to framing members, such as top or bottom plates. They can be used for air sealing a variety of connections.

Adhesives are most successful when used between the surfaces of the members being connected. They adequately fill and span gaps of $1 / 8$ inch or less. In practice, what they effectively do is ensure contact between the pieces "glued together." They do not perform well when used as a caulk for corner joints or where there will be differential movement of the two members being joined. The purpose of an adhesive is to bond things together. If one member moves, the adhesive and its associated fasteners try to bring the other member with it. They are not intended to be flexible.

There are many adequate products on the market. You should select brands and types that are suited for the intended applications. For example, if plywood is to be sealed as a subfloor, the adhesive should be designed for potentially wet and cold job conditions.

Available products include the following:

STA-STUCK - 400

Manufactured by Specialty Chemicals Co., Elk Grove Village, IL 60007: 312-766-2400.

HENRY 113 Drywall Stud Mastic

Manufactured by The WW Henry Company, Huntington Park, CA 90255 ; 213-583-4961.

LUMBERLOCK All Weather Construction Adhesive

Manufactured by Miracle Adhesives Corp., Bellmore, NY 11710.

PL200 and PL500 Construction Adhesives

Manufactured by ChemRex Inc., Contech Brands, Minneapolis, MN 53435. 
Caulks

Uses

\section{Caulk Products}

\section{Gaskets}

\section{Uses}

Unlike adhesives, caulks are usually formulated to carry out two tasks-- to senl itself to other materials and to fill space. They work best in holes and gaps between $1 / 8$ inch and $1 / 4$ inch. Somewhat larger gaps can be filled, but they may require successive applications. The urethane products have greater success all filling the larger gaps. Products with superior performance, in general, are the silicones, urethanes, and the newer "siliconized" acrylics. These waterresistant products have good elastic characteristics and good adhesion to most building materials. They also tend to resist shrinkage.

Common joints for which caulks may be the seal of choice include the gap between the gypsum wallboard and a subfloor, the cracks around door and window trim, and anound cutouts in gypsum board for electrical boxes.

Available products include the following:

AIR-LOCK, Water-Based Duct Sealant

Manufactured by RectorSeal Corp., 2830 Produce Row, Houston, TX 77023: 800-231-3345.

Mu 35 Acrylic Rubber Sealant with Silicone Manufactured by Macklanburg-Duncan, P.O. Box 25188 , Oklahoma City, OK $73125 ; 800-654-8454$.

MAGIC SEAL 25 Year, Siliconized Acrylic Latex

Manufactured by Magic Seal Corp., St. Louis, MO 63043.

SONOLASTIC NP.1, Urethane Sealant

Manufactured by Sonneborn Building Products, a division of Rexnord Chemical Products Inc., Minneapolis, MN 55435; 612-835-3434.

SIKAFLEX 1A, Urethane Sealant

Manufactured by SIKA Corp., Construction Products Division, P.O. Box 297. Lyndhurst, NJ 07071; 201-933-8800.

Gaskets serve much the same space-filling function as caulks, but they also are easy to use between materials, as the adhesives are used. They are preformed elastomeric materials that may or may not have an adhesive backing. Their primary purpose is to provide air-barrier continuity in the hidden seams between materials.

Gaskets are commonly available in the form of tapes, backe:- rods, and other profiles that may have specific application. They are typically made from EPDM, polyethylenes, neoprenes, or other plastics.

Joints for which gaskets seem especially suited are the drywall to woodframing connections at floors, walls, and ceilings. They need to be compressed in order to function, because they have no permanent adhesion to the surfaces they lie between. Because of their ability to be compressed and return to their original dimension, they are appropriate to use when large amounts of joint movement are expected. Another advantage of gaskets is their ability to allow one component to slide slowly by another while maintaining contact. 


\section{Gasket Products}

\section{Foams}

\section{Uses}

\section{Sources of Foam Products}

Available products include the following:

ADA GASKET, EPDM rubber gasketing (specifically designed for ADAtype construction)

Distributed by Resource Conservation Technology, 2633 North

Calvert St., Baltimore, MD 21218; 301-366-1146.

"P" Strip Weatherstrip, EPDM Rubber, Self adhesive Distributed by Whole Energy \& Hardware, 103 Peavy Rd., Bay 1, Chaska, MN 55318; 1-800-544-2986,

V 770 NORSEAL, Vinyl foam tape

Manufactured by NORTON Sealants and Performance Plastics, 1377 9th Ave., San Francisco, CA 94122; 415-923-1476.

SURE SEAL and ULTRA SEAL, Saturated foam gaskets

Distributed by DENARCO Sales Company, Elkhart, IN 46515; 219-294-7605.

Expanding foams are most commonly used on the site to seal openings larger than $1 / 2$ inch. They are also applied to penetrations like plumbing supply lines and telephone and electrical wiring. Foams are usually either "triple" expanding or only slightly expanding. The expanding formulations have more applications for large holes, though some care is required when filling a hole that is also deep. The nonexpanding foams seem to work well where there is a gap that cannot be caulked successfully, such as the shim space around windows and doors.

The foams come in canisters ranging in size from 12 ounces to 10 pounds. They are available with a simple throw-away, one-time spout or with a hose and reusable applicator tip. Another application tool is a type of applicatorgun assembly that allows for the adjustment of the foam bead size.

Possible sources of foam products include the following:

Various foams and gun-type systems

Whole Energy \& Hardware, 103 Peavy Rd., Bay 1, Chaska, MN 55318; 800-544-2986 or $612-448-1668$.

HILTI Fastening Systems, Foam and applicator gun systems HILTI Fastening Systems, 3487 NW Yeon Ave., Portland, OR 97201; 503-227-6323.

CON VENIENCE Products, Touch'n Seal Instant Sealant, Foams and systems

Convenience Products Inc., 4205 Forest Park Blvd., St. Louis, MO 63108; 314-535-6226.

FOMO Products Inc., Foam and applicator systems FOMO Products Inc., 2775 Barber Rd., P.O. Box 1078, Norton, OH 44321; 216-753-4585.

PURFIL 1G, an interesting new product which uses CFC-142B as the expansion agent. (According to advertising information, this chemical is 95 percent less damaging to the ozone layer than conventional CFCs.) Contact Peter ConIon at Todol Products, Inc., 20 Charles St., Natick, MA (01760; 508-879)-1741. 


\section{Sheet Materials Uses}

\section{Sources of Sheet Materials}

Some penetrations, such as plumbing drains and vents, are not effectively sealed with caulks or foans. In places where the holes are irregular or there is no backing to foam against, even a seal that looks good at the time of appliciltion may fail over time as a result of movement or shrinkage and expansion. In these cases, the answer may be to use a small sheet of elastic material with a hole cut out for the penetration. The hole in the sheet will remain snug around the pipe and the sheet can be caulked and stapled to the framing.

Pleces of rubber can be cut from old truck inner tubes. The rubber is about $1 / 8$ inch thick or greater and can be cut into 6"x 6" pieces or whatever serves the' purpose. If the inner tube material is too small or unavailable, sheet EPDM or neoprene are both possible altematives for this type of application. Large pleces of sheet EPDM have been used to help seal off the penetration of large ducts through blocking or subfloors. Be sure to maintain adequate fireblocking.

Possible sources of sheet material include the following:

Resource Conservation Technology Inc., 2633 North Calvert St, Baltimore, MD 21218; 301-366-1146.

Whole Energy \& Hardware, 103 Peavy Rd., Bay 1, Chaska, MN 55318 ; 1-800-544-2986. 
Appendix D Detail Drawings 
Figure 1. Typical "ADA" Ceiling Detail

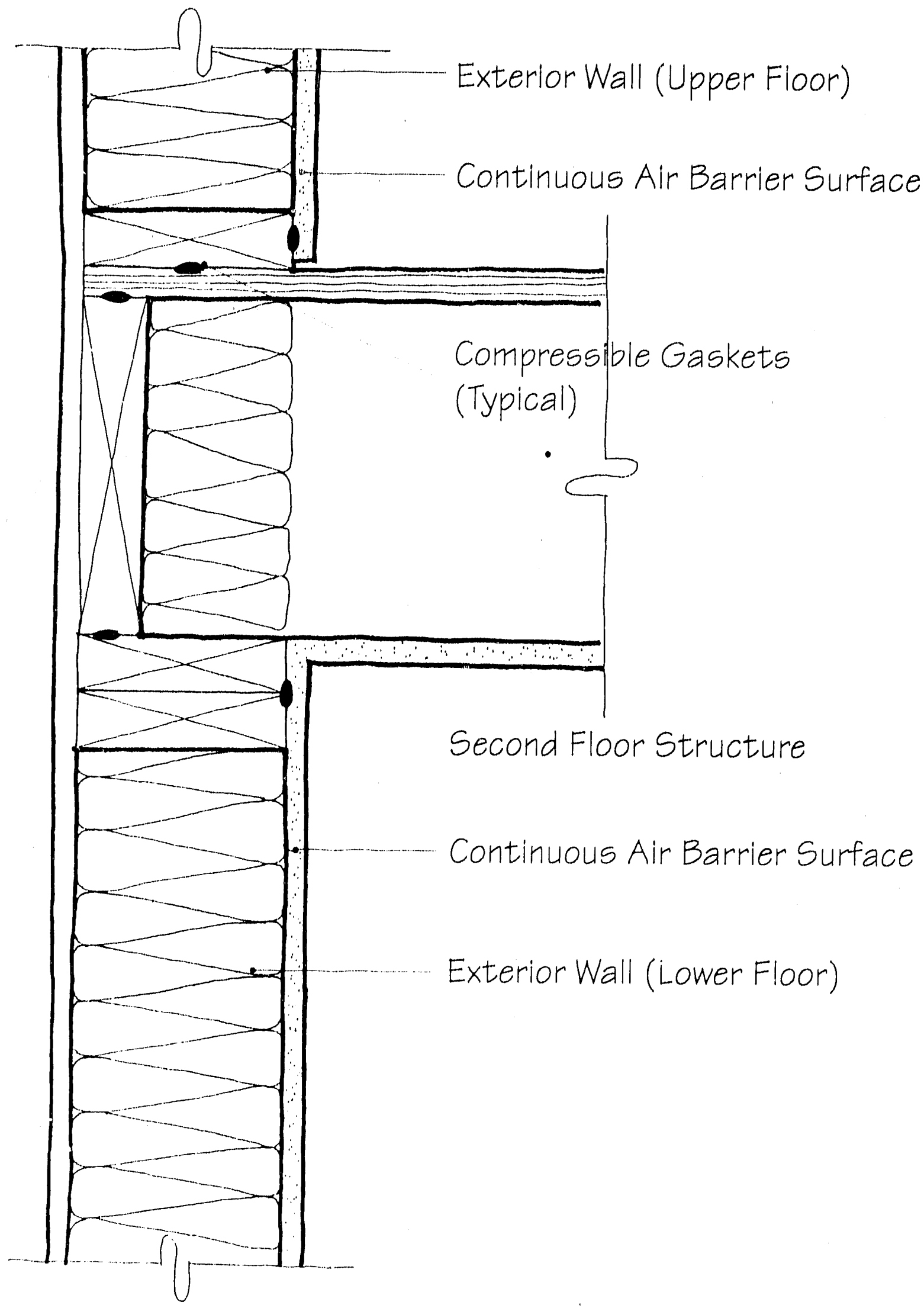


Figure 2. Intersection of Interior and Exterior Wall

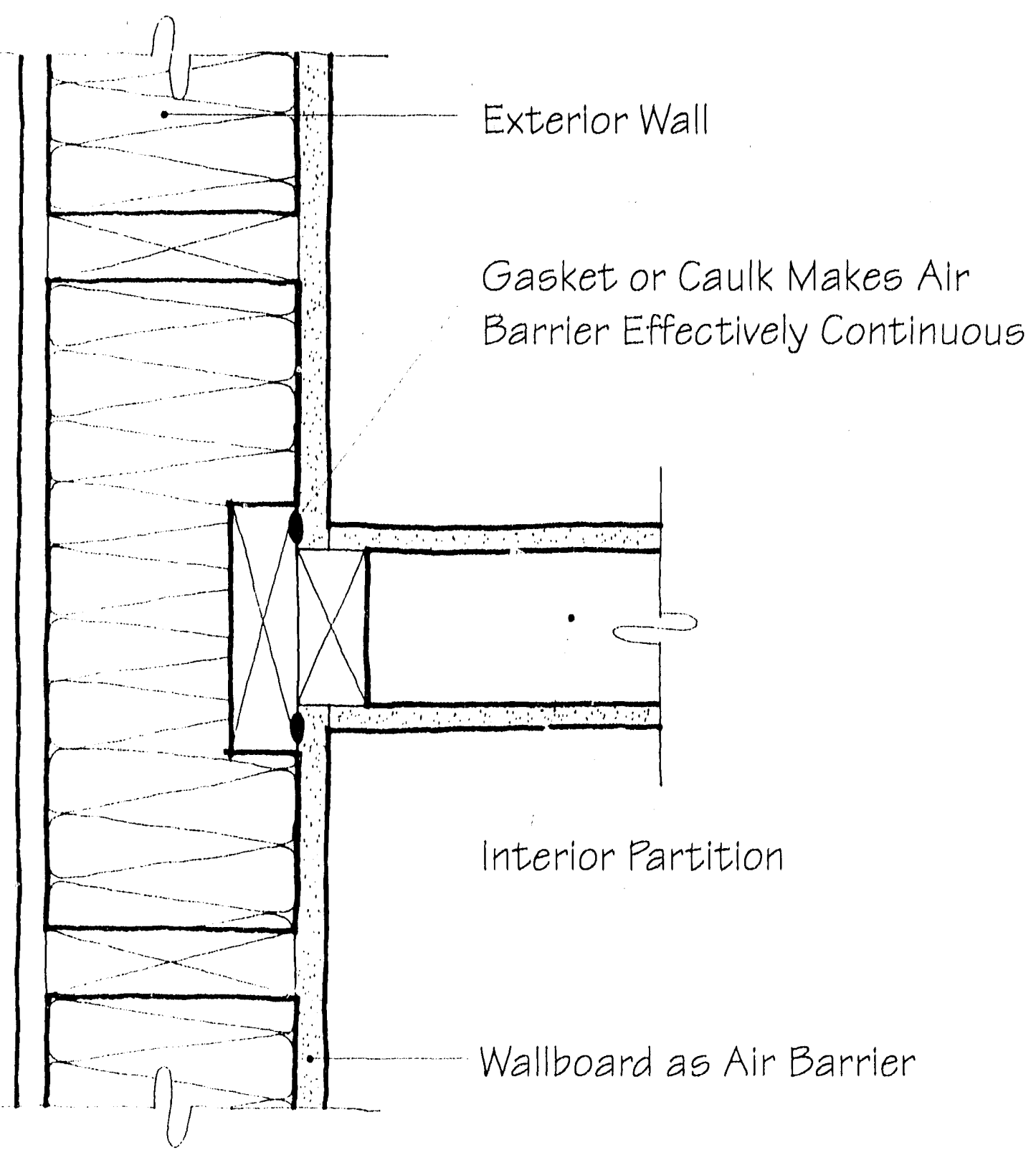


Figure 3. "ADA" Wall Section at First and Second Floors

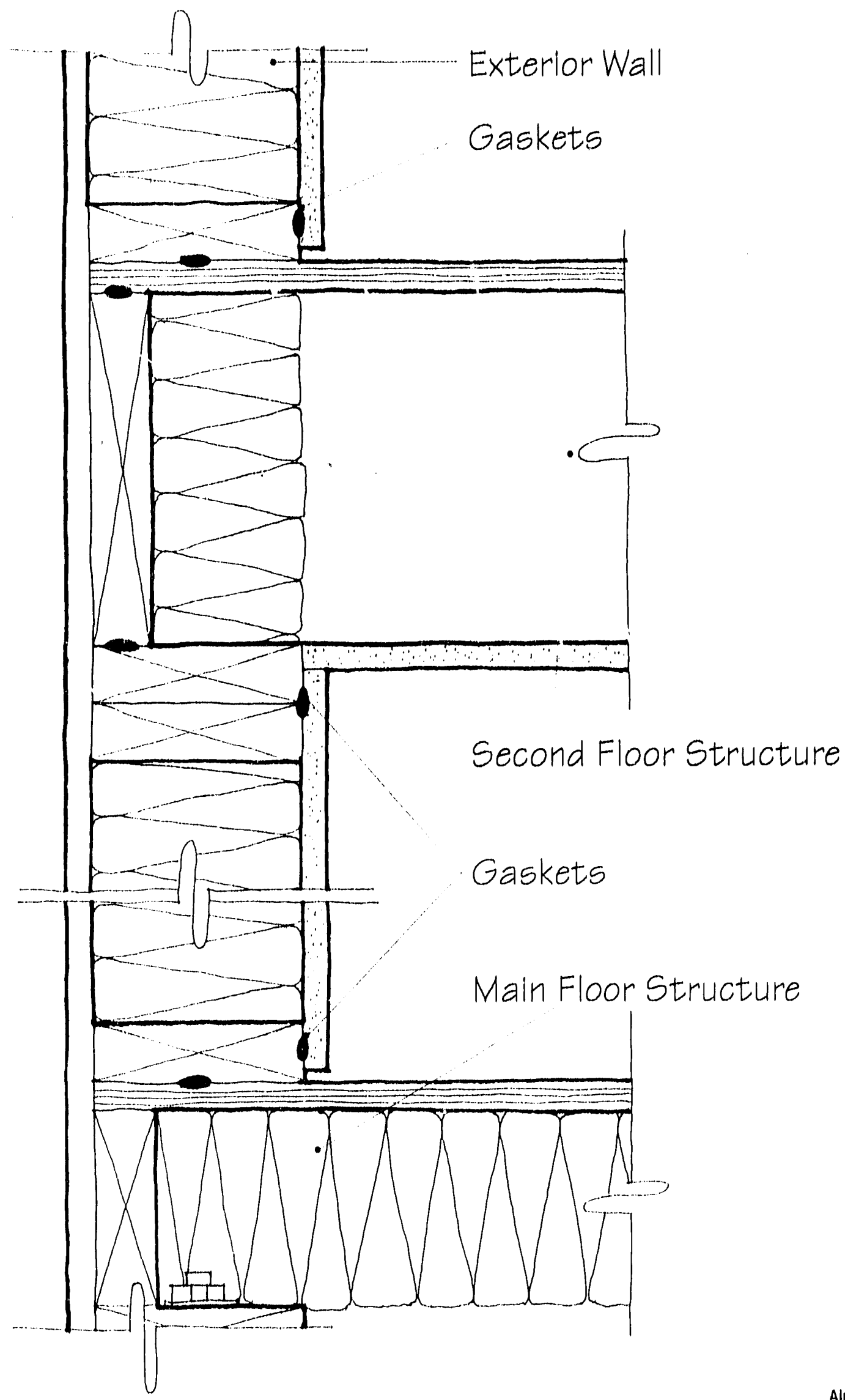




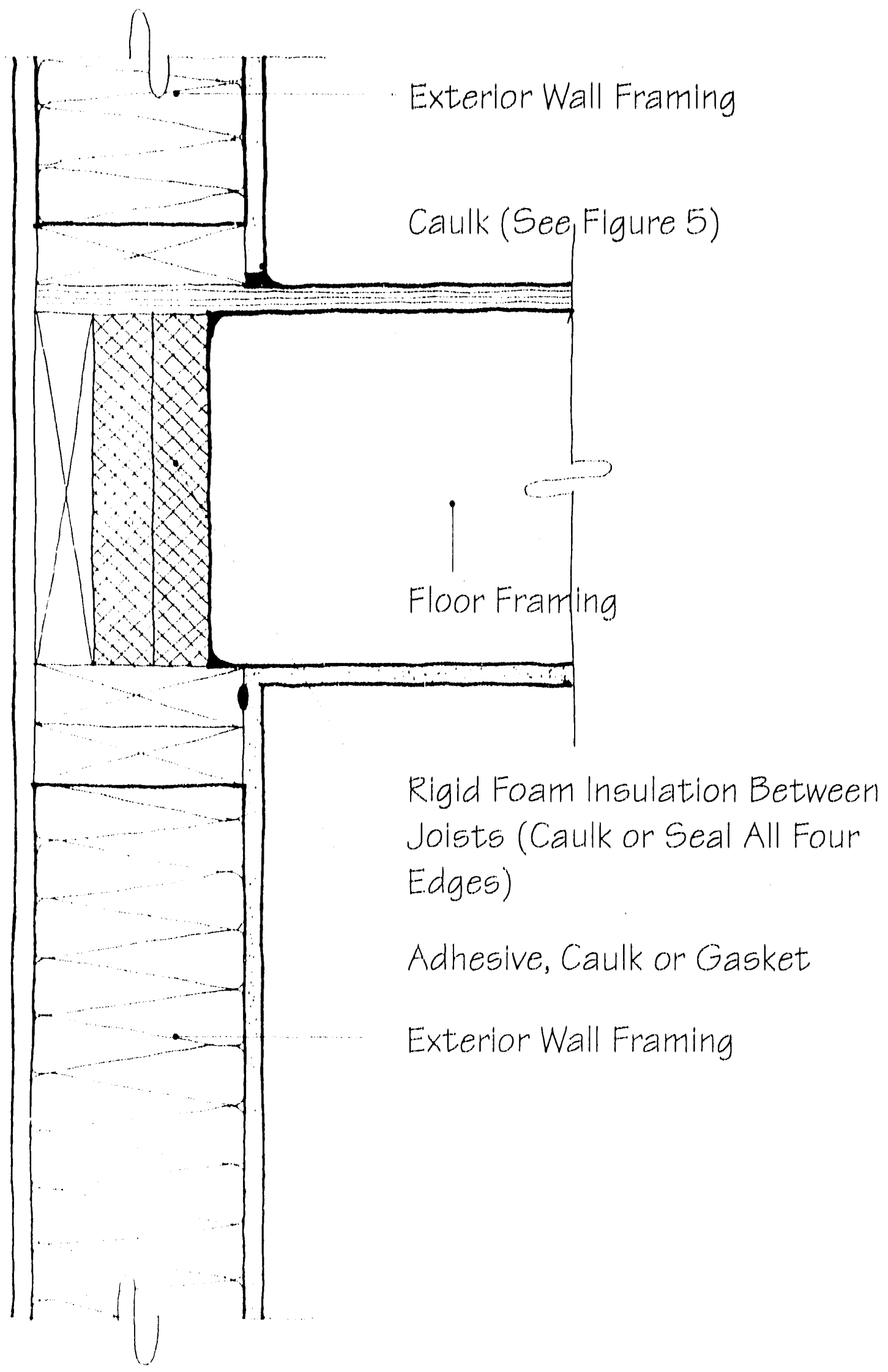




\section{Figure 5. SIMPLE॰CS Ceiling at Exterior Wall/ Floor Joint}

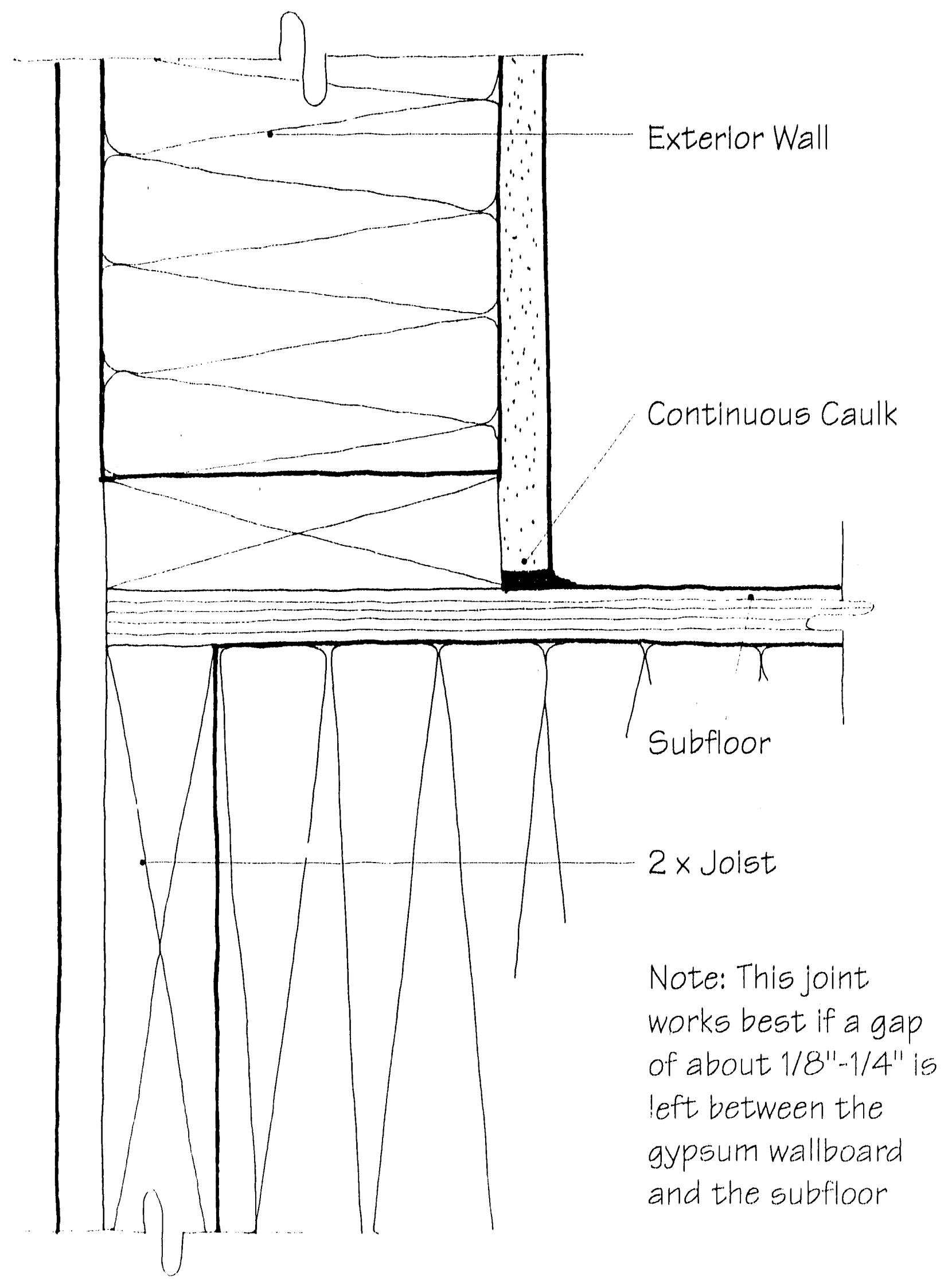




\section{Figure 6a. Intersection of Interior and Exterior Wall (Type 1)}
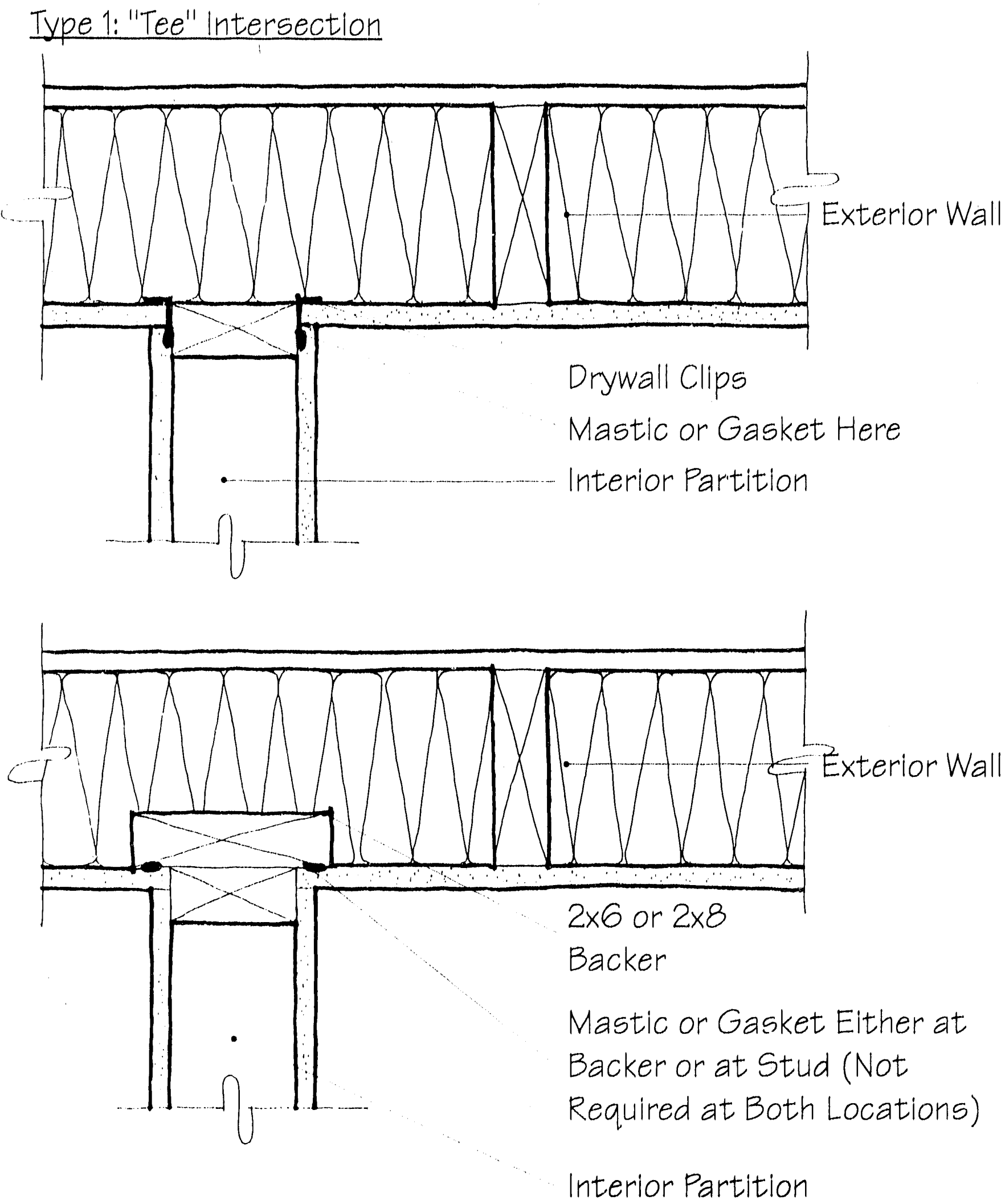
Figure 6b. Intersection of Interior and Exterior Wall (Type 2)

Type 2: Intersection With $ə$ Corner

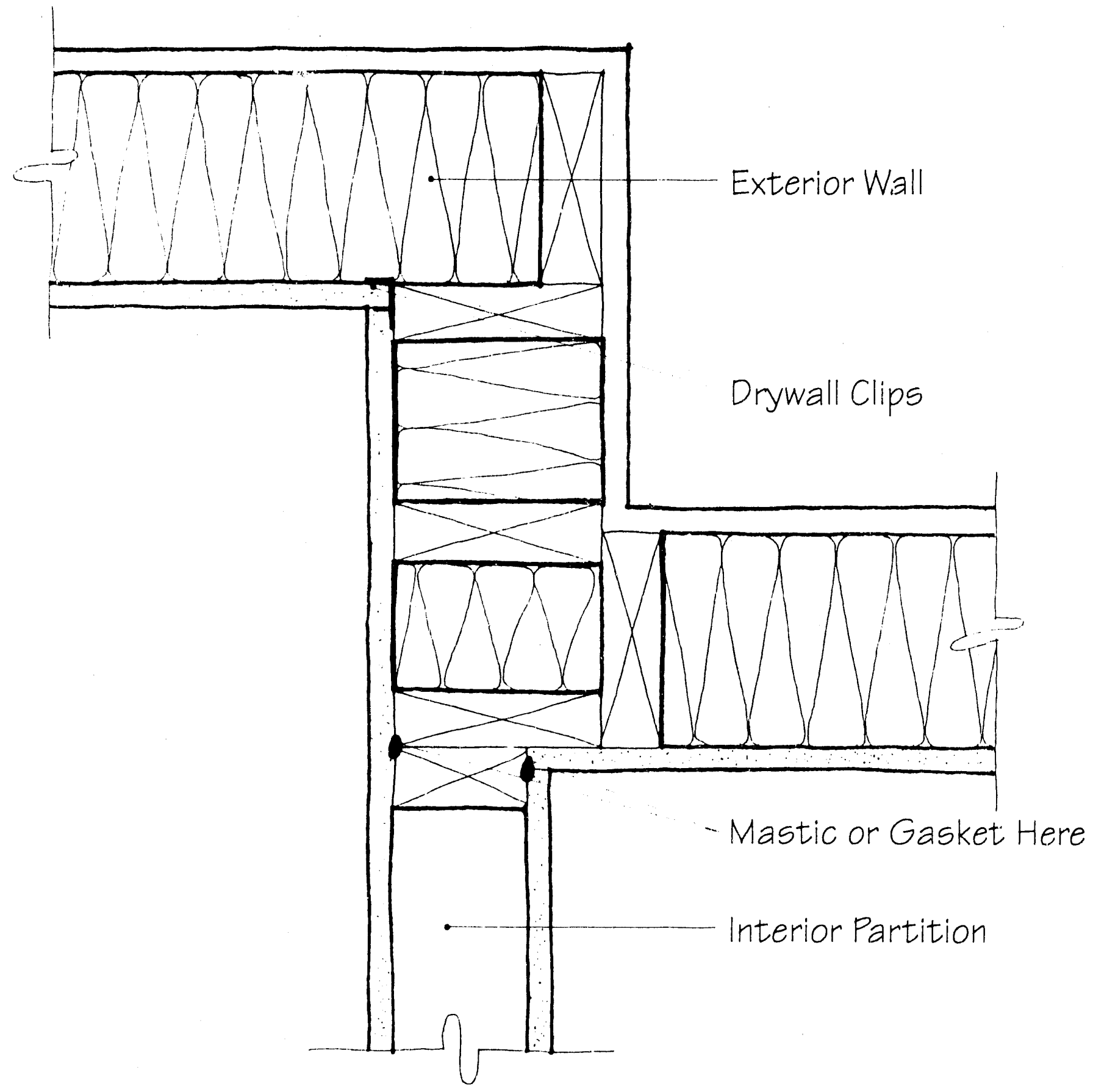




\section{Figure 7. Intersection of Interior Wall and Exterior Ceiling}

Bottom Chord of Truss

Drywall Clips

Recommended to

Minimize Uplift
Partition

Top Plate

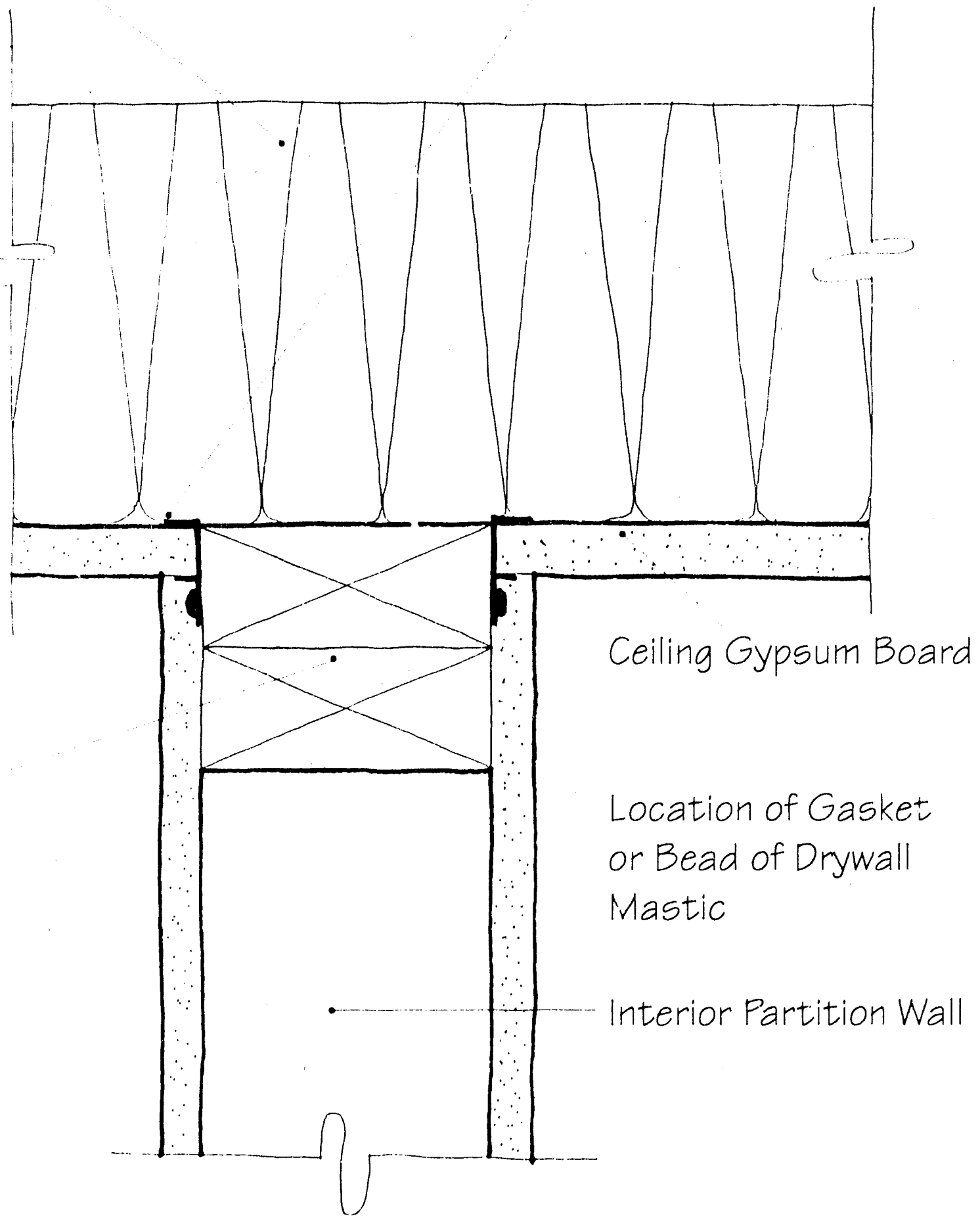




\section{Figure 8a. Sealing at Plumbing Penetrations}

Plumbing Penetrations

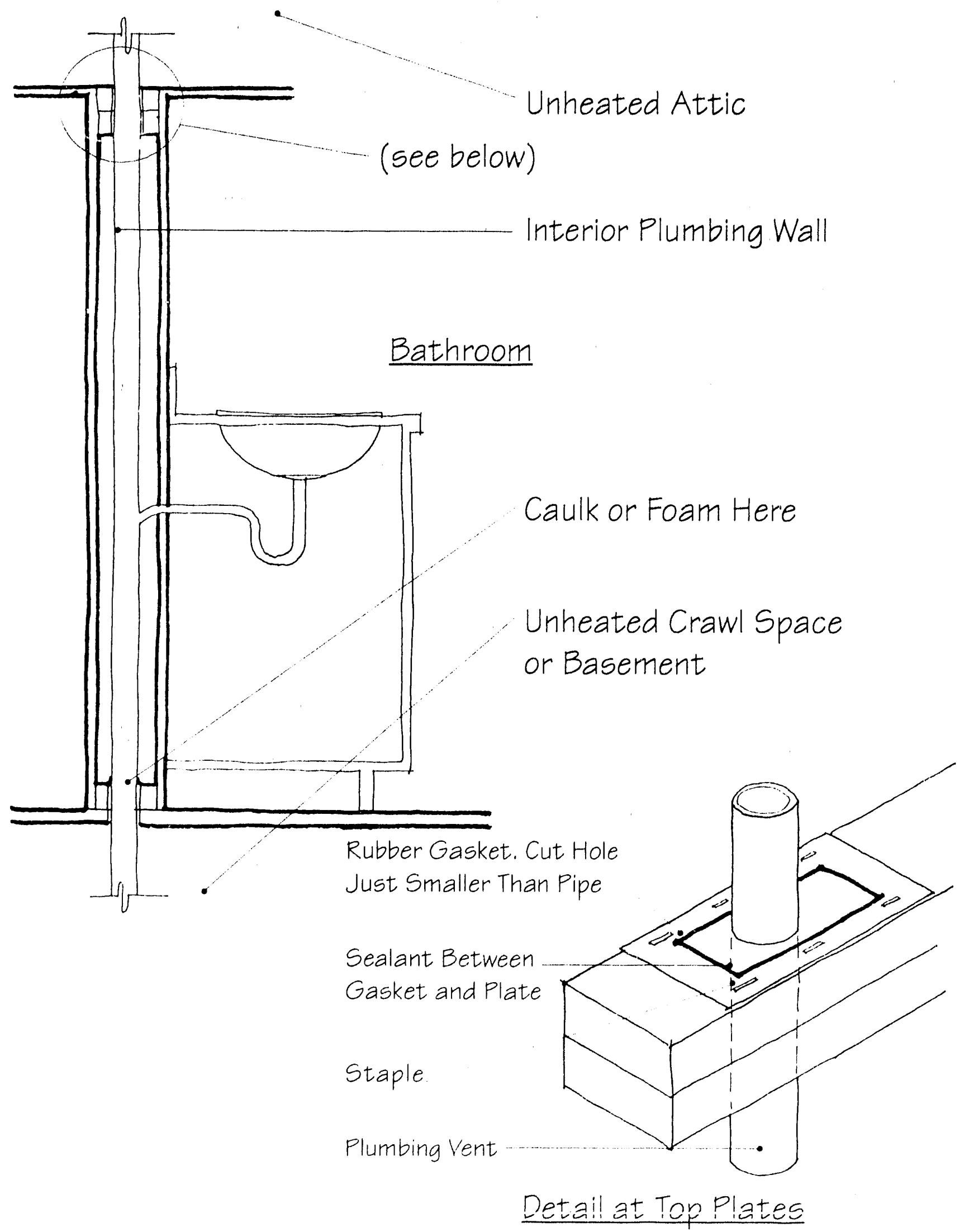


Figure 8b. Sealing for Bathtub at Subfloor Cutout

Bathtub Drain Connection Hole

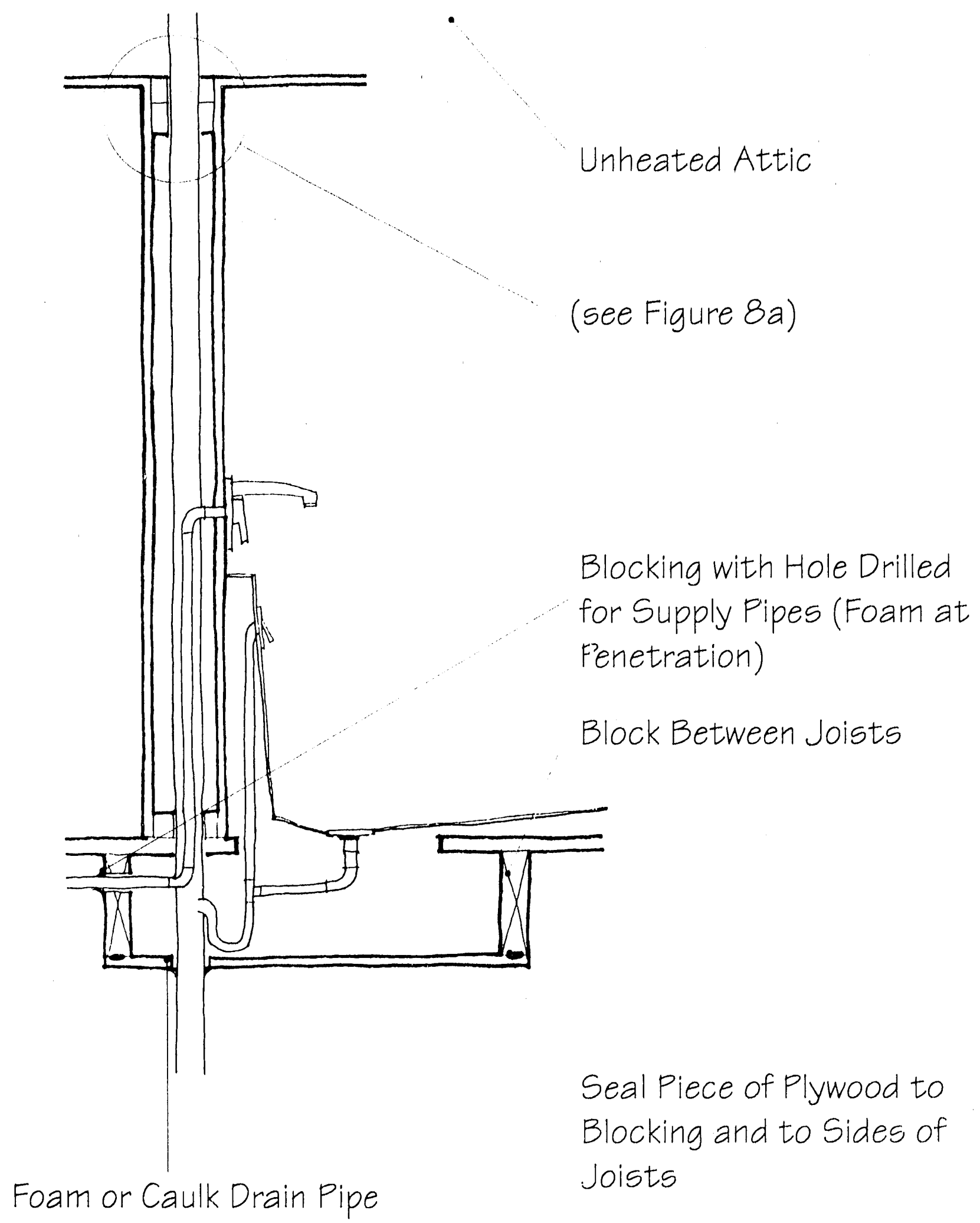


Figure 9. Sealing Electrical Penetrations

Electric Wiring Details

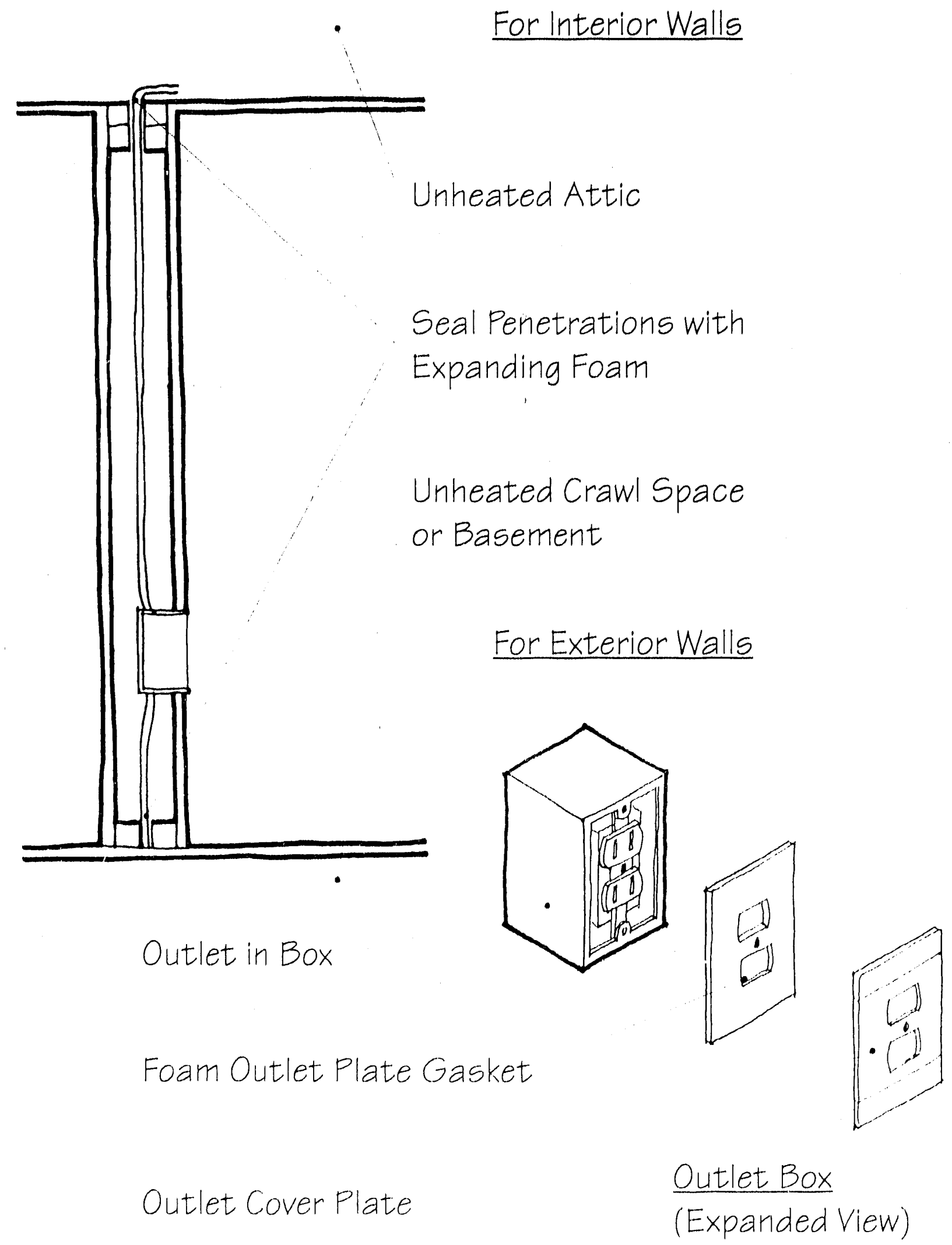



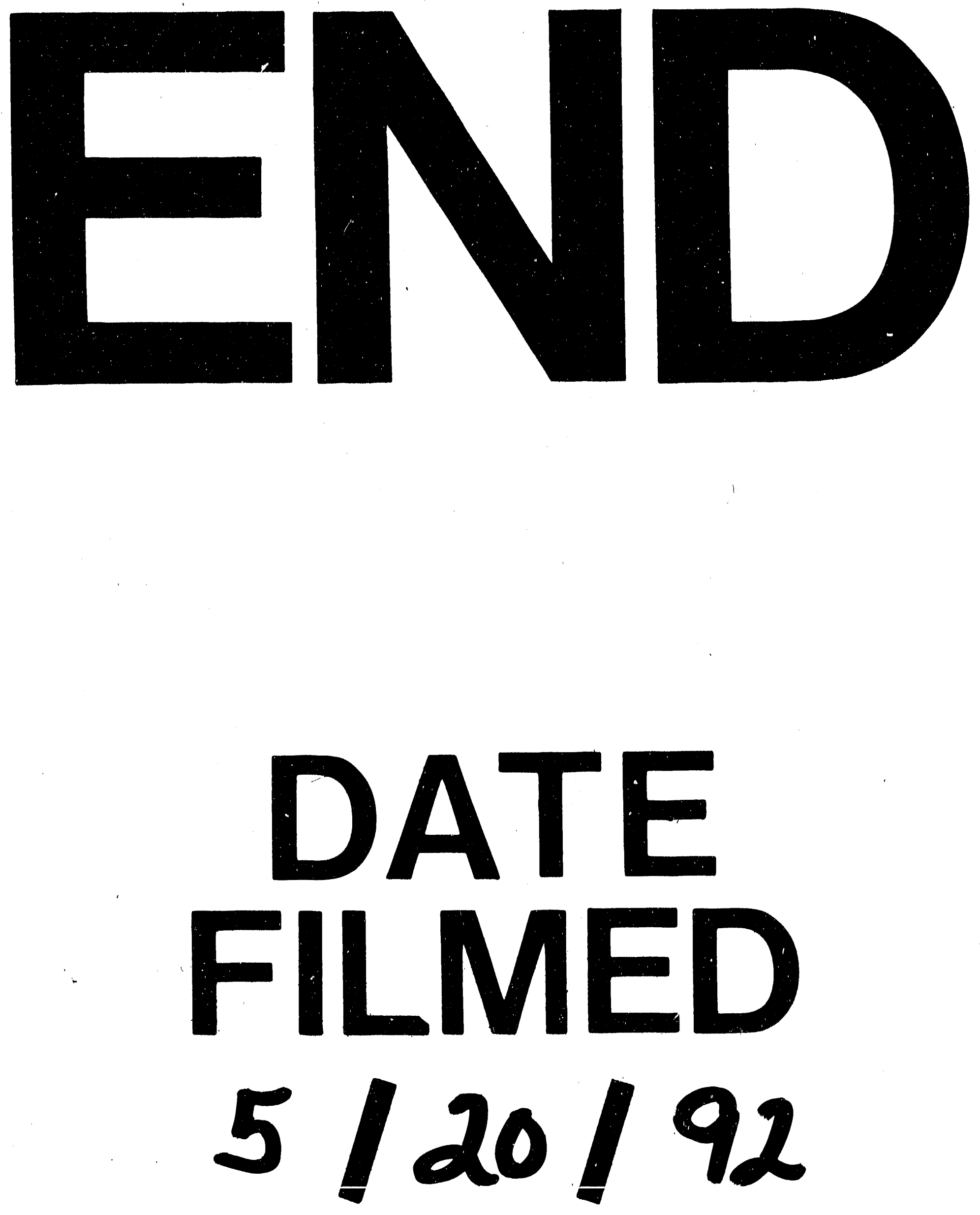
